NUREG/CR-6557

\title{
Development of the Magnescope as an Instrument for In Situ Evaluation of Steel Components of Nuclear Systems
}

Manuscript Completed: July 1997

Date Published: August 1997

Prepared by

D.C. Jiles, Y. Bi, S.B. Biner

Ames Laboratory

Iowa State University

Ames, IA 50011

\section{Prepared for}

Division of Engineering Technology

Office of Nuclear Regulatory Research

U.S. Nuclear Regulatory Commission

Washington, DC 20555-0001

NRC Job Code G6394

\section{DISCLAIMER}

This report was prepared as an account of work sponsored by an agency of the United States Government. Neither the United States Government nor any agency thereof, nor any of their employees, makes any warranty, express or implied, or assumes any legal liability or responsibility for the accuracy, completeness, or usefulness of any information, apparatus, product, or process disclosed, or represents that its use would not infringe privately owned rights. Reference herein to any specific commercial product, process, or service by trade name, trademark, manufacturer, or otherwise does not necessarily constitute or imply its endorsement, recommendation, or favoring by the United States Government or any agency thereof. The views and opinions of authors expressed herein do not necessarily state or reflect those of the United States Government or any agency thereof.

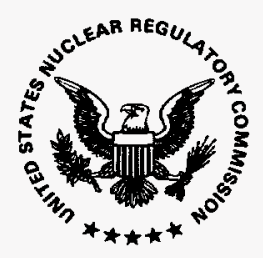




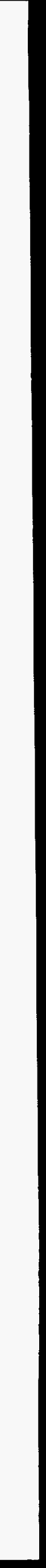




\section{DISCLAMMER}

Portions of this document may be illegible in electronic image products. Images are produced from the best available original docoment. 



\begin{abstract}
Fatigue damage causes continuous, cumulative microstructural changes in materials and the magnetic properties of steels are sensitive to these microstructural changes. The work therefore focused on the relationship between fatigue damage and the measured magnetic properties of different steels under a variety of fatigue conditions. The project also investigated the feasibility and applicability of magnetic inspection techniques for non-destructive evaluation of fatigue damate.

From the results of a series of fatigue tests, conducted on different steels under both low-cycle and high-cycle fatigue conditions, the magnetic properties, such as coercivity, remanence and Barkhausen effect, were found to change systematically with fatigue

damage. The magnetic properties showed significant changes, especially during early stage of the fatigue and also at the end of the fatigue lifetime. An approximately linear relationship between the mechanical modulus and magnetic remanence was observed and was explained by a model developed in this study to describe the dynamic changes in magnetic and mechanical properties.

The results of this research demonstrated that magnetic measurements are suitable for non-destructive evaluation of fatigue damage in steels such as A533B steel and Cr-Mo steels. The magnetic measurement techniques have been incorporated into instrumentation for in-situ evaluation of steel structures and components.
\end{abstract}





\section{CONTENTS}

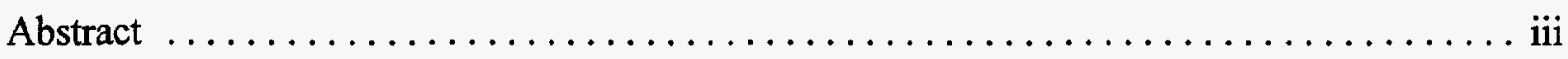

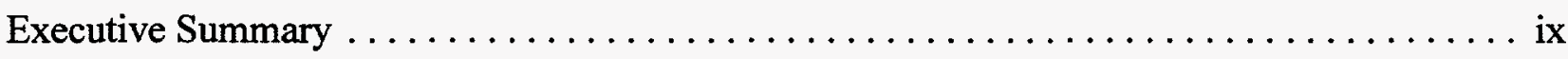

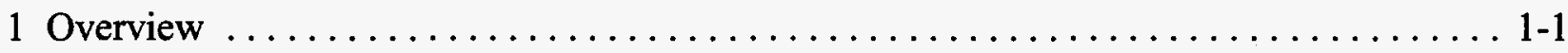

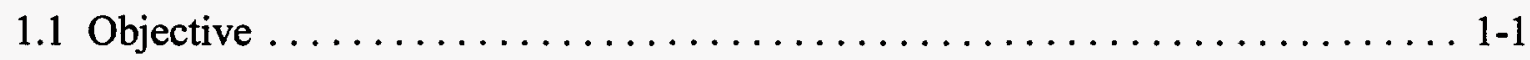

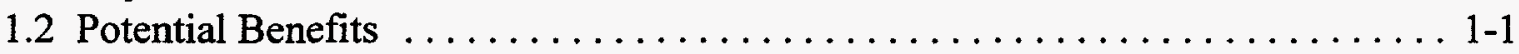

1.3 Summary of Main Tasks $\ldots \ldots \ldots \ldots \ldots \ldots \ldots \ldots \ldots \ldots \ldots \ldots \ldots \ldots \ldots \ldots \ldots \ldots, 1$

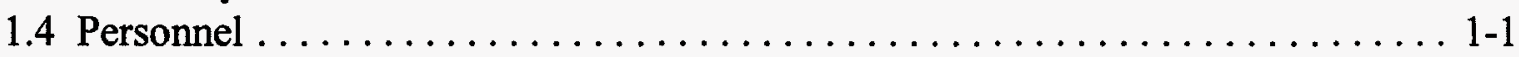

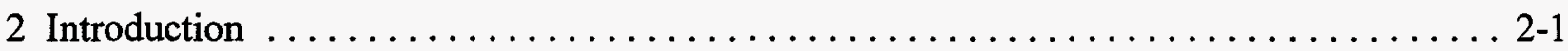

3 Materials, Instrumentation and Experimental Procedure $\ldots \ldots \ldots \ldots \ldots \ldots \ldots \ldots \ldots \ldots \ldots .1$

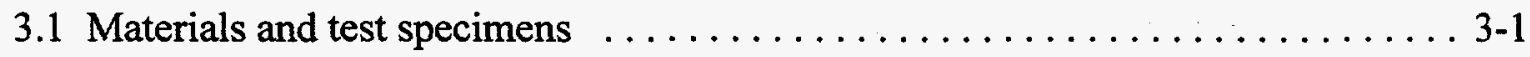

3.2 Instrumentation $\ldots \ldots \ldots \ldots \ldots \ldots \ldots \ldots \ldots \ldots \ldots \ldots \ldots \ldots \ldots \ldots \ldots \ldots \ldots \ldots \ldots, 1$

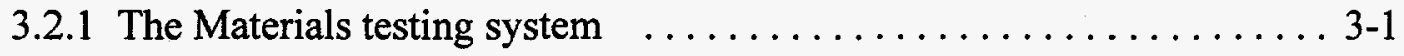

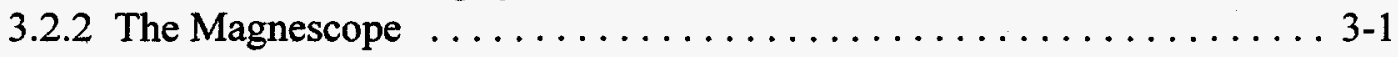

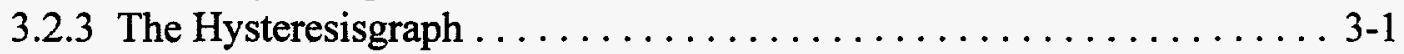

3.2.4 The Magneprobe $\ldots \ldots \ldots \ldots \ldots \ldots \ldots \ldots \ldots \ldots \ldots \ldots \ldots \ldots \ldots \ldots \ldots \ldots, 1$

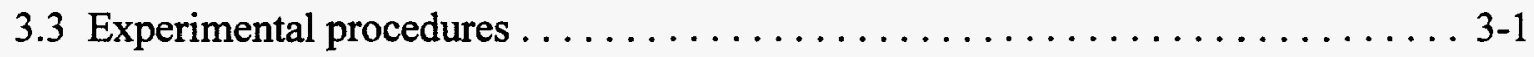

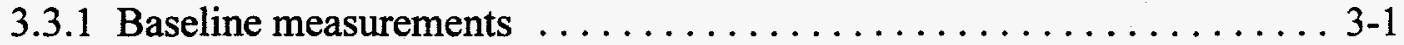

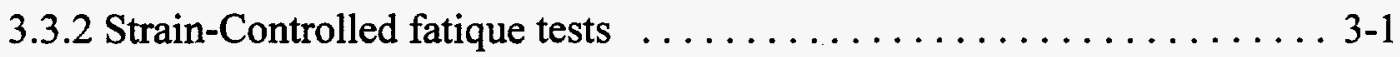

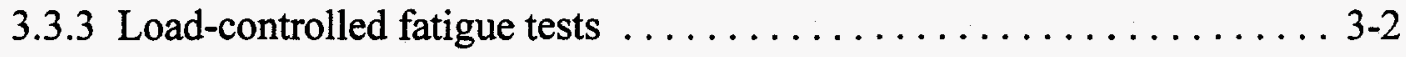

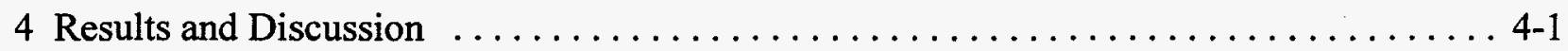

4.1 Milestones progress review . . . . . . . . . . . . . . . .

4.2 Relationship between mechanical properties and magnetic properties ....... 4-2

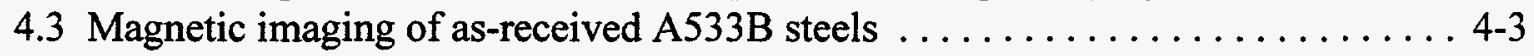

4.4 Strain-controlled fatigue tests on A533B steel $\ldots \ldots \ldots \ldots \ldots \ldots \ldots \ldots .4 .3$

4.5 Effect of applied stress on magnetic properties in strain-controlled fatigue . . . . 4-4

4.6 Load-controlled fatigue tests on A533B steel . . . . . . . . . . . . . . . 4-4

4.7 Strain-controlled fatigue tests on Cr-Mo steel $\ldots \ldots \ldots \ldots \ldots \ldots \ldots \ldots .4$

4.8 Modeling of strain-controlled fatigue $\ldots \ldots \ldots \ldots \ldots \ldots \ldots \ldots \ldots \ldots \ldots, 5$

4.9 Relationship between fatigue lifetime and magnetic properties $\ldots \ldots \ldots \ldots \ldots$. 4-6 


\section{CONTENTS (continued)}

5 Conclusions

6 References

\section{Appendix}

A Tables and Figures

A-1

\section{Tables}

1 Chemical compositions of steels involved in this project

2 The effect of microstructures on magnetic properties, stable modulus, hardness and fatigue lifetime

3 The baseline magnetic properties of two A533B steels

(Hc, Br, Loss and Vrms)

4 The baseline magnetic properties of the Cr-Mo steels

(Hc, Br, Loss and Vrms)

\section{Figures}

1 Micrograph of the first A533B steel $\ldots \ldots \ldots \ldots \ldots \ldots \ldots \ldots \ldots \ldots \ldots \ldots \ldots$

2 Micrograph of the second A533B steel $\ldots \ldots \ldots \ldots \ldots \ldots \ldots \ldots \ldots \ldots \ldots$

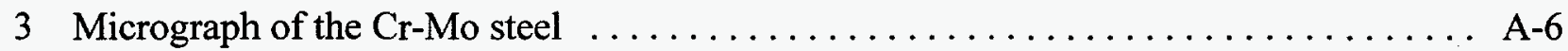

4 Two dimensional magnetic image (coercivity) on the surface of the first A533B steel.

5 Two dimensional magnetic image (coercivity) on the surface of the second A533B steel

6 The effect of strain-controlled fatigue on coercivity in one specimen cutting from first $\mathrm{A} 533 \mathrm{~B}$ steel block along rolling direction (group A) 


\section{CONTENTS (continued)}

7 The effect of strain-controlled fatigue on coercivity in one specimen cutting from first A533B steel block normal to rolling direction (group B)

8 The effect of strain-controlled fatigue on coercivity in one specimen machined from the second A533B steel (Group C).

9 The effect of strain-controlled fatigue on remanence in one specimen cutting from first A533B steel block along rolling direction (group A)

10 The effect of strain-controlled fatigue on remanence in one specimen cutting from first A533B steel block normal to rolling direction (group B) .

11 The effect of strain-controlled fatigue on remanence in one specimen machined from the second A533B steel (Group C)

12 The effect of strain-controlled fatigue on hysteresis loss in one specimen cut from first A533B steel block along rolling direction (group A)

13 The effect of strain-controlled fatigue on hysteresis loss in one specimen cut from first A533B steel block normal to rolling A-16 direction (group B)

14 The effect of strain-controlled fatigue on hysteresis loss in one specimen machined from the second A533B steel (Group C)

15 The effect of strain-controlled fatigue on Barkhausen emissions in one specimen machined from the first A533B steel block along

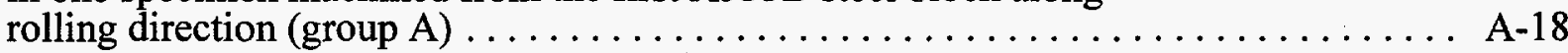

16 The effect of strain-controlled fatigue on Barkhausen emissions in one specimen machined from first A533B steel normal to rolling direction (group B)

17 The effect of strain-controlled fatigue on Barkhausen emissions in one specimen machined from the second A533B steel (Group C)

18 Relationship between mechanical modulus and measured remanence in strain-controlled fatigue on sample NRC-B5

19 Relationship between mechanical modulus and measured remanence in strain-controlled fatigue on sample NRC-A5

20 The effect of both fatigue damage and stress on measured coercivity in strain-controlled fatigue

21 The effect of both fatigue damage and stress on measured remanence in strain-controlled fatigue 


\section{CONTENTS (continued)}

22 The effect of fatigue damage on coercivity of A533B steel in load-controlled fatigue

23 The effect of fatigue damage on remanence of A533B steel in load-controlled fatigue

24 The effect of fatigue damage on hysteresis loss of A533B steel in load-controlled fatigue

25 The Wöhler curve ( $S-N_{f}$ curve) of A533B steel in load-controlled fatigue

26 The effect of cyclic loading amplitude on the evolution of the magnetic properties ( coercivity) in the A533B steel

27 The effect of cyclic loading amplitude on the evolution of the magnetic properties ( remanence) in the A533B steel

28 The effect of strain-controlled fatigue on magnetic coercivity in one specimen (NRC-E1) machined from Cr-Mo steel

29 The effect of strain-controlled fatigue on magnetic remanence in one specimen (NRC-E1) machined from Cr-Mo steel

30 The effect of strain-controlled fatigue on hysteresis loss in one specimen machined from Cr-Mo steel

31 The effect of strain-controlled fatigue on Barkhausen emissions in one specimen machined from Cr-Mo steel

32 Experimental and modeled curves about the dynamic change in mechanical modulus resulted from strain-controlled fatigue damage

33 Experimental and modeled curves about the dynamic change in mechanical modulus resulted from strain-controlled fatigue damage

34 Experimental and modeled curves about the dynamic change in measured remanence resulted from strain-controlled fatigue damage

35 Experimental and modeled curves about the dynamic change in measured remanence resulted from strain-controlled fatigue damage

36 Relation between the fatigue lifetime and baseline coercivity in one group of A533B steel 


\section{EXECUTIVE SUMMARY}

Fatigue damage causes continuous, cumulative microstructural changes in materials and the magnetic properties of steels are sensitive to these microstructural changes. This work therefore focused on the relationships between fatigue damage and the measured magnetic properties of different steels under a variety of fatigue conditions. The project also investigated the feasibility and applicability of magnetic inspection techniques for non-destructive evaluation of fatigue damage.

From the results of a series of fatigue tests, conducted on different steels under both low-cycle and high-cycle fatigue conditions, the magnetic properties, such as coercivity, remanence and Barkhausen effect, were found to change systematically with fatigue damage. The magnetic properties showed significant changes, especially during the early stage of the fatigue and also at the end of the fatigue lifetime. An approximately linear relationship between the mechanical modulus and magnetic remanence was observed and was explained by a model developed in this study to describe the dynamic changes in magnetic and mechanical properties.

The results of this research demonstrated that magnetic measurements are suitable for non-destructive evaluation of fatigue damage in steels such as A533B steel and $\mathrm{Cr}$-Mo steels. These magnetic measurement techniques have been incorporated into instrumentation for in-situ evaluation of steel structures and components. 



\section{OVERVIEW}

\subsection{Objective}

The major objective of this research was to extend earlier research into the use of magnetic techniques for nondestructive evaluation of nuclear systems ['] in order to establish their utility for evaluation of cumulative fatigue damage. The project investigated the effects of different modes of fatigue, compositional changes and variable amplitude loading on fatigue lifetime and magnetic properties. These results were used to assess the predictive capabilities of magnetic measurement techniques for remaining fatigue life estimation.

Furthermore the project was used to evaluate the applicability and feasibility of magnetic measurement techniques, such as the Magnescope [ $\left.{ }^{2}\right]$ and the Magneprobe [3] which measure the magnetic hysteresis properties and magnetic Barkhausen emissions, for non-destructive in-situ evaluation of fatigue damage.

\subsection{Potential Benefits}

The evaluation of fatigue damage is very important for critical components which are exposed to cyclic loading conditions during their service lifetime. Currently destructive tests are used on specimens taken from components in service. This clearly has detrimental effects on the components, even when repairs are subsequently made, and the situation is all the more unsatisfactory when the sample which was removed proved to be in adequate condition for continued service. The cost of these destructive tests is also not to be underestimated. Considering the detrimental effects which destructive evaluation techniques have on the components, viable methods for nondestructive evaluation of fatigue damage are highly desirable.

In terms of the measurement of the intrinsic properties of a material, the magnetic measurement methods are very promising techniques for evaluation of fatigue damage $\left[{ }^{4}\right]$. This is because the magnetic methods can be usefully applied before the initiation of fatigue cracks not only after fatigue crack nucleation like other non-destructive evaluation techniques, such as ultrasonic and $\mathrm{X}$-ray method.

If methods can be identified which can accurately determine accumulated fatigue damage in a material, and thereby give an estimation of the remaining fatigue life, the impact on the cost of maintenance and safe operation of large installed structures such as nuclear power plants will be enormous. Therefore the present work was designed to identify those magnetic measurements which could be used to assess the condition of steel components without removal of material.

\subsection{Summary of Main Tasks}

In order to study the effect of fatigue damage on the measured magnetic properties and to show a relationship between the fatigue damage accumulation and the magnetic properties, we prepared A533B and Cr-Mo steel fatigue specimens; performed pre-fatigue magnetic measurements; subjected fatigue specimens to cyclic loading in strain-controlled mode or load-controlled mode; took magnetic hysteresis and magnetic Barkhausen emission measurements at predetermined fatigue cycle intervals; investigated the evolution of the magnetic properties throughout the fatigue lifetime; and studied the relationship between the pre-fatigue magnetic measurements and fatigue test results, particularly fatigue lifetimes.

\subsection{Personnel}

The following persons were involved in the project. Dr. D. C. Jiles, Senior Physicist at Ames Laboratory and Professor of Materials Science and Engineering and Professor of Electrical Engineering, Dr. S. B. Biner, Metallurgist at Ames Laboratory and Associate Professor of Materials Science and Engineering were the principle investigators of this project. Ying $\mathrm{Bi}$, a graduate student working for his Master's degree in Electrical Engineering, performed laboratory fatigue tests and magnetic measurements. 



\section{INTRODUCTION}

The evaluation of fatigue damage is critically important for components which are subjected to severe cyclic operating stresses during their service lifetimes. In nuclear power systems, where A533B steel is widely used for the structural components, the cyclic stress resulting from thermal expansion often creates low-cycle, straincontrolled fatigue conditions. Therefore an evaluation technique which can monitor the fatigue progress and predict the impending fatigue failure non-destructively is highly desirable from the viewpoints of both safety and economy.

During fatigue there are continuous and cumulative microstructural changes in materials, such as the motion and redistribution of dislocations, formation of slip bands, nucleation and propagation of fatigue cracks $\left.{ }^{5}\right]$. The magnetic properties of materials are very sensitive to these microstructural changes $\left[{ }^{6},{ }^{7}, 8\right]$. Therefore, it should be possible to evaluate the fatigue damage in materials by magnetic measurements.

Previous works at Iowa State University had led to the development of two new magnetic NDE instruments, the Magnescope [2], and the Magneprobe [3]. The bulk magnetic signatures and the surface layer Barkhausen emissions of the materials were measured via surface transducers or sensors. Both of these techniques are completely nondestructive in nature. The demonstrated sensitivity of magnetic properties of steels to their mechanical condition suggests that these methods should provide the tools required for the assessment of the mechanical state of steel structural components. In this project these two instruments were used as the principal means for nondestructive evaluation of the materials.

The Magnescope is a computerized system which measures bulk magnetic properties of materials. Under the action of a magnetic field, the motion of domain walls is impeded by the pinning sites which consist of all microstructural defects, such as the dislocations, grain boundaries and second phase inclusions. It is clear from the earlier work $\left[{ }^{9},{ }^{10},{ }^{11}\right]$ that the mechanical treatment of the material (e.g. applied stress, plastic deformation, cyclic loading, surface preparation, shot peening and fatigue exposure) significantly changes the measured magnetic properties. For these reasons, and in view of the sensitivity of the properties to these treatments, magnetic property measurements provide a useful addition to the conventional nondestructive evaluation methods of ultrasonics, eddy currents and radiography for the assessment of steel structures and components.

The Magneprobe is based on an entirely different principle [3]. It measures high frequency discontinuous changes in magnetization, known as the Barkhausen effect, at the surface of the material as the applied magnetic field is varied. The Barkhausen emissions are attributed mostly to the sudden irreversible motion of domain walls when they break away from pinning sites under the action of a changing magnetic field. These pinning sites could be grain boundaries, dislocations, precipitates, inclusions, microcracks and other inhomogeneities. The measurement of the Barkhausen signals can be used to determine information about the microstructure and stress state of the material in the near surface layer $\left[{ }^{12}\right]$. These micromagnetic emissions occur mostly at frequencies in the range 20 $\mathrm{kHz}-200 \mathrm{kHz}$, and therefore can only be detected over a short distance from the point of origin. In steels these distances are up to $0.15 \mathrm{~mm}$ (at $200 \mathrm{kHz}$ ) and $0.5 \mathrm{~mm}$ (at 20 $\mathrm{kHz}$ ). Therefore by measuring the micromagnetic emissions over a range of frequencies the properties can be probed at depths of up to typically $0.5 \mathrm{~mm}$ in steels. Recent research results have shown that the stress in the surface of steel components can be deduced from the Barkhausen effect measurement $\left[{ }^{13}\right]$, and it is this surface stress that is most critical in the development of fatigue cracks in the material leading to its ultimate failure.

Considering the short penetration depth in steels, the Barkhausen emissions give information only about the surface layer, which makes Barkhausen measurements suitable for determination of the formation 
of extrusions and intrusions due to slip at which fatigue crack nucleation takes place during the cyclic deformation. On the other hand, magnetic hysteresis measurements, which are performed under a quasi-DC magnetic field, allow deeper penetration of the field, and can give information about microstructure in the bulk of the material. The combination of these two measurements should result in improved in-situ monitoring of fatigue damage.
Based on these established techniques as viable methods for evaluation of steel structures and components, magnetic measurements were made during fatigue tests conducted on both A533B and Cr-Mo steels. The magnetic properties were found to change systematically with fatigue damage. The results of this project demonstrate that magnetic inspection techniques, represented by the Magnescope and the Magneprobe, can be used successfully for the NDE of fatigue damage. 


\section{MATERIALS, INSTRUMENTATION AND EXPERIMENTAL PROCEDURE}

\subsection{Materials and test specimens}

Two widely used steels for high pressure or high temperature application were investigated in this project, namely, A533B pressure vessel steel and Cr-Mo piping steel. Two different batches of A533B steels were obtained from Oak Ridge National Laboratory from two different sources. They had similar chemical compositions (Table 1), but different microstructures (Fig. 1, Fig. 2). Twenty-six tensile specimens were machined from the two A533B steels for the strain-controlled fatigue tests. Six tensile specimens, denoted by group A, were cut from the first A533B steel block in the rolling direction. Six tensile specimens, denoted by group B, were cut from the first A533B steel block normal to rolling direction. Five tensile specimens, denoted by group $\mathrm{C}$, were cut from the second A533B steel block. Nine tensile specimens, denoted by group $\mathrm{D}$, were cut from the first A533B steel block along rolling direction for the load-controlled fatigue tests performed in the second year of the project. Cr-Mo steel was obtained from General Atomics. It had significantly lower carbon concentration and higher $\mathrm{Cr}$ and $\mathrm{Mo}$ concentration than the A533B steel (Table 1) and larger grain size (Table 2 and Fig. 3). Nine tensile specimens, denoted by group E, were cut from the $\mathrm{Cr}-\mathrm{Mo}$ steel pipe along the axial direction for strain-controlled fatigue tests during the second year of the project.

\subsection{Instrumentation}

\subsubsection{The Materials testing system}

A computer controlled $100 \mathrm{KN}$ servohydraulic material test system, MTS 880 , was used. All fatigue tests were performed on this system in either strain-controlled mode or load-controlled mode.

\subsubsection{The Magnescope}

This was developed by the Center for NDE, Iowa State University. The Magnescope is a magnetic hysteresis measurement system which operates through a surface sensor. All in situ magnetic hysteresis measurements and baseline magnetic measurements were made by the Magnescope.

\subsubsection{The Hysteresisgraph}

The Hysteresisgraph is a standard item of magnetic measurement equipment that was used to make the baseline magnetic hysteresis measurements. The instrument used in this projected was a Walker Magnetics Group, MH-10-20 model hysteresisgraph.

\subsubsection{The Magneprobe}

This was developed by Center for NDE, Iowa state University. The Magneprobe is a Barkhausen emissions measurement system. All the baseline measurements and in situ measurements of Barkhausen signals were made using the Magneprobe.

\subsection{Experimental procedures}

\subsubsection{Baseline measurements}

Before subjecting specimens to cyclic load, baseline magnetic measurements were made on the machined tensile specimens using the Magnescope, the Hysteresisgraph, and the Magneprobe. Point-to-point magnetic measurements were made on the polished surfaces of the two A533B steel blocks.

\subsubsection{Strain-controlled fatigue tests}

The tensile specimens were subjected to cyclic strain with a strain amplitude of 0.003 at a frequency of $2 \mathrm{~Hz}$ using the MTS 880 system. At pre-determined intervals, the MTS was paused in zero-strain condition and the magnetic measurements were made through a surface sensor using the Magnescope and the Magneprobe.

In order to study the effects of stress on the measured magnetic properties, during some of these strain-controlled fatigue tests, magnetic measurements ( hysteresis and Barkhausen emissions measurement ) also were made under zero load, fixed tensile load and fixed compressive load. 


\subsubsection{Load-controlled fatigue tests}

The yield strength of the first A533B steel was obtained by a tensile test. Several loadcontrolled fatigue tests with different applied stress amplitudes below the yield stress were then conducted to determine the $S-N_{f}$ curve. Based on the $S-N_{f}$ curve, fatigue tests with different stress amplitudes were applied during a single fatigue lifetime. These were performed in order to make a comparison with the prediction of Miner's rule. During the load-controlled fatigue tests, the cyclic loading frequency was changed depending on the fatigue lifetime under the applied load amplitude, so that the fatigue test could be completed in an appropriate period. The magnetic measurements were made under zero load conditions and the intervals between magnetic measurements were adjusted based on the fatigue lifetime. 


\section{RESULTS AND DISCUSSION}

\subsection{Milestones progress review}

1. Two A533B steels were obtained from Oak Ridge National Laboratory. The first of these was a A533B steel block with dimensions of $18 \times 12 \times 3$ (inch) ${ }^{3}$ and with a known rolling direction. A second A533B steel block, had dimensions of $9 \times 11 \times 10$ (inch $^{3}$. According to the supplier, the two A533B steels were serviced aged and obtained from different sources.

2. Chemical analysis indicated $t$ a.hat there was no significant difference in chemical compositions between the two A533B steels, although metallographic examination revealed significant differences in grain size.

3. Seventeen tensile test specimens were machined from the two sets of A533B steels. Six were machined from the first A533B steel along the rolling direction, Six were machined from the first A533B steel normal to the rolling direction, and five were machined from the second A533B steel from five different positions

4. A surface sensor for the Magneprobe, which can apply a varying magnetic field to the material and pick-up the Barkhausen emissions from it, was designed and made. The sensor has a close fit to the geometry of the test specimen so that the Barkhausen signals can be detected efficiently.

5. Baseline magnetic measurements were made using the Magnescope, the Hysteresisgraph and the Magneprobe. The baseline magnetic measurements revealed that there are variations in magnetic properties from sample to sample, and there was significant difference in mean values of magnetic properties between specimens from the two A533B steels.

6. 2-D magnetic imaging using the Magnescope was made on the surfaces of the two A533B steel blocks. The measurements demonstrated the ability and feasibility of the Magnescope as a technique for non-destructive evaluation of these materials.

7. Strain-controlled fatigue tests with a fixed strain-amplitude of $0.003(0.3 \%)$ at a frequency of $2 \mathrm{~Hz}$ were conducted on machined A533B steel tensile specimens. Magnetic measurement were made throughout the fatigue lifetime at intervals of 1000 cycles. Towards the end of fatigue life the interval was reduced so that the rapid change in magnetic properties could be observed. The magnetic properties, such as coercivity, remanence, hysteresis loss and Barkhausen signals, were found to change systematically with the fatigue damage throughout the fatigue lifetime. The variations in magnetic properties during the fatigue tests are shown in the results section, together with a discussion of the underlying mechanism behind the observed changes.

8. During some of the strain-controlled fatigue tests, the magnetic measurements were made not only under zero-strain conditions, but also under zero load, fixed tensile load and fixed compressive load conditions in order to study the effects of stress-state on magnetic properties. The results shown in subsequent sections revealed that although the applied stress had significant effects on the measured magnetic properties, magnetic properties still showed significant changes at the end of fatigue life.

9. Nine tensile specimens were machined from the first A533B steel along the rolling direction for load-controlled fatigue tests. Baseline magnetic measurements were made on these specimens using the Magnescope, the Hysteresisgraph and the Magneprobe.

10. Load-controlled fatigue tests with only tensile loading were conducted. The fatigue lifetimes were much longer than the fatigue lifetime with $R=-1$ at the same maximum load.

11. Load-controlled fatigue tests with $R=-1$ were conducted and magnetic 
measurements were made at predetermined intervals. The magnetic properties were also found to change with fatigue damage systematically and the evolution of the magnetic properties was found to depend on the applied stress amplitude. After applying different load amplitude below the yield stress, the $S-N_{f}$ curve were obtained.

12. Based on the $S-N_{f}$ curve, different stress amplitudes were applied in one fatigue lifetime period in order to make the comparison with the Miner's rule prediction for A533B steel.

13. Cr-Mo piping steel was obtained. Chemical analysis and metallographic examination revealed a lower carbon concentration and larger grain size.

14. Nine tensile specimens were machined from the Cr-Mo steel along the axial direction of the pipe. Baseline magnetic measurements were made on the nine samples using the Magnescope, the Hysteresisgraph and the Magnescope. The results showed a significantly lower magnetic properties and higher Barkhausen emissions. These are consistent with the known lower carbon concentration and larger grain size in the Cr-Mo steel.

15. Strain-controlled fatigue tests with the same strain amplitude of 0.003 and the same cyclic frequency of $2 \mathrm{~Hz}$ were conducted on the specimen machined from the Cr-Mo steel. Magnetic measurement were made throughout the fatigue lifetime at intervals of 1000 cycles. Towards the end of fatigue life, the intervals were reduced so that the rapid change in magnetic properties could be observed. The measured magnetic properties were also found to change systematically with fatigue damage although longer fatigue lifetimes were observed.

16. Rockwell Hardness tests were made on the two A533B steels and the Cr-Mo steel. The results indicated a difference between the two A533B steel and a significant difference between A533B steel and Cr-Mo steel. These were consistent with the results of chemical analysis and magnetic baseline measurements.

\subsection{Relationship between mechanical properties and magnetic properties}

The mechanical properties, such as hardness, yield stress, fatigue lifetime, and stable modulus of a material are affected by their chemical compositions and microstructures. On the other hand, the magnetic properties of the material are also affected by microstructure and chemical composition. Therefore, it was expected that there should be some relationships between the mechanical properties and magnetic properties. In this project, these relationships were studied on samples among different groups on a statistical basis, and on samples from one group, respectively.

The two A533B steels involved in this study had similar chemical compositions (Table 1) but different grain sizes (Fig. 1 and Fig. 2). The mechanical properties, fatigue properties and the measured magnetic properties showed differences as indicated in Table 2.

Due to the microstructural differences, the two groups exhibited significant differences in baseline magnetic properties, Rockwell hardness and fatigue lifetime under the same strain-controlled fatigue conditions. The group with smaller grain size showed higher hardness, higher coercivity and shorter fatigue lifetime as shown in Table 2

Grain boundaries provide one type of pinning site. Pinning sites affect domain wall motion under the action of a magnetic field. The smaller grain size leads to larger grain boundary area, more pinning sites per unit volume, and hence a higher coercivity. The material with smaller grain size was also mechanically harder. Under stresscontrolled fatigue, this higher hardness corresponds to a longer fatigue lifetime. However, under strain-controlled fatigue, the fatigue lifetime of smaller grain size specimens was found to be significantly shorter than that of specimens of A533B steel with larger grain size.

Chemical analysis (Table 1 ) revealed a significantly lower carbon concentration and 
larger grain size (Table 2) in the $\mathrm{Cr}-\mathrm{Mo}$ steel than in the A533B steel. These were both believed to be responsible for the lower Rockwell hardness, longer fatigue lifetime under the same strain-controlled fatigue condition, lower stable modulus (Table 2), lower baseline coercivity and higher Barkhausen emissions. Like the grain boundaries, the carbides act as pinning site which impede the motion of domain walls under the action of a magnetic field. Lower carbon concentration therefore offers fewer pinning sites, hence, lower baseline coercivity.

The results of this study indicated that through their microstructures the mechanical properties of steels, such as the hardness, fatigue lifetime, are related to their magnetic properties, such as coercivity and Barkhausen emissions and that as a consequence magnetic measurements can be used to evaluate microstructures nondestructively.

\subsection{Magnetic imaging of as-received A533B steels}

The point-to-point distribution in the magnetic hysteresis parameters of the polished surface of the two A533B steels were measured using the Magnescope using a surface sensor. The variation in coercivity on the surfaces of the two A533B steel blocks are shown in Fig. 4 and Fig. 5. The variation in properties near the edges of the magnetic image was attributed to the cutting process which induced stresses and changed the magnetic properties. The variation in the two images were related to either the localized surface defects resulting from the cutting and polishing process, or the localized residual stresses.

These two magnetic images exhibit the utility of the Magnescope as a technique for non-destructive evaluation of steel components. These magnetic images can be used to characterize the material and locate areas which have high concentrations of defects, such as high dislocation density and residual stresses.

\subsection{Strain-controlled fatigue tests on A533B steel}

A series of strain-controlled fatigue tests were performed on the specimens machined from the two A533B steels. The results of magnetic measurements showed that magnetic properties, such as coercivity, remanence, hysteresis loss and Barkhausen emissions, systematically changed with the fatigue damage as shown in Fig. 6 to Fig. 17. These results showed increases in coercivity with fatigue, particularly towards the end of fatigue lifetime, and decreases in remanence. The changes in remanence seemed to track the mechanical modulus.

At the beginning of fatigue, during fatigue softening, the pre-existing dislocations move to the grain boundaries. This decrease in dislocation density within the grains offers smaller resistance to further strain, therefore the mechanical modulus decreased with fatigue softening. On the other hand, decrease in dislocation density also offers less pinning sites to impede the motion of domain wall under the action of a magnetic field and therefore this resulted in a decrease in coercivity and remanence. The decrease in dislocation density also provided more room for the discontinuous motion of the domain walls, resulting in an increase in Barkhausen emissions.

During the stable stage of fatigue, the microstructures reached a dynamic equilibrium for the applied load and for this material. Corresponding to the stabilization of fatigue, the measured remanence also showed stabilization. It was noted that measured coercivity began to gradually increase earlier than when the modulus and remanence began to significantly decrease. This occured typically at about $70 \%$ of fatigue lifetime and was attributed to the fatigue slip bands near surface. Under cyclic loading, more and more slip bands, which were in the form of intrusions and extrusions, were created near the surface. These slip bands are micro-discontinuity points, and result in a leakage field nearby. At the same time, these slip bands also act as pinning sites to impede the domain wall motion near the surface. Therefore the measured coercivity gradually increased with slip band formation.

During the last stage of fatigue, because the propagation of fatigue cracks reduced the area bearing the applied load, the load needed to reach the same strain decreased. 
Correspondingly the measured modulus decreased. On the other hand, a fatigue crack, which usually initiates at the surface and propagates from that point, is a discontinuity plane within the magnetic material. The discontinuity plane results in an increase in leakage magnetic field nearby. The measured coercivity, which was the measured magnetic field when the magnetic induction in the magnetic circuit was zero, increased after the propagation of the fatigue crack. The fatigue crack changes the distribution of the magnetic field, causing demagnetization effects, so that measured remanence decreased as the fatigue crack propagated.

The observed relationship between the magnetic remanence and the mechanical modulus at all stages of fatigue life would seem to indicate a close relationship between the two mediated via the microstructural changes. In this study, an approximately linear relationship between mechanical modulus and magnetic remanence was found as shown in Fig. 18 and Fig. 19. The relationship indicated that the mechanical condition of steels during fatigue could be evaluated by the magnetic remanence measurements.

\subsection{Effect of applied stress on magnetic properties in strain-controlled fatigue}

Stress affects dislocation density in materials, and hence affects the measured magnetic properties of steels. There is evidence that certain magnetic hysteresis parameters are strongly influenced by the magnitude and the direction of the applied and residual stresses. In order to distinguish the variation in the magnetic properties due to the fatigue damage from variations due to applied or residual stresses, another series of fatigue experiments was conducted. During these experiments, magnetic measurements were taken not only at zero strain condition but also at fixed tensile and compressive stresses. The variation of coercivity and remanence with the number of fatigue cycles under different stress types, viz., compressive and tensile, is shown in Fig. 20 and Fig. 21.

It can be seen that coercivity and remanence were influenced significantly by the type of applied stress in particular compressive stress seemed to have much greater effect on these properties than tensile stress. The application of compressive stress increased the measured coercivity value and decreased the measured remanence value. The coercivity and remanence measured under $158 \mathrm{MPa}$ tensile stress were very close to measured under zero strain condition. This effect is simply due to the similarity in conditions under "zero strain" and $158 \mathrm{MPa}$ tensile stress. Because in order to make the system reach zero strain condition after several cycles, the system had to exert about $133 \mathrm{MPa}$ tensile stress on the sample. This result of the study indicates that "in service stress" affects the measured magnetic properties during fatigue, but fatigue damage can still be detected and separated from the effects of stress by magnetic measurements, provided magnetic measurements are made consistently under identical stress levels.

\subsection{Load-controlled fatigue tests on A533B steel}

A series of stress-controlled fatigue tests with different stress amplitudes were performed on the specimens machined from the first sample of A533B steel along the rolling direction. The magnetic properties, such as coercivity, Fig. 22, remanence, Fig. 23 and hysteresis loss, Fig. 24, also were found to change systematically with the fatigue damage. A Wöhler curve $\left(S-N_{f}\right.$ curve) for the A533B steel was obtained in this study as shown in Fig. 25.

Under a smaller stress amplitude, which resulted in high-cycle fatigue, the magnetic properties were found to remain stable while the strain amplitude remained stable. Under a larger stress amplitude, on the other hand, the magnetic properties were found to evolve sooner than the strain amplitude. The higher applied stress amplitude resulted as expected in a shorter fatigue lifetime and the evolution of the magnetic properties was also found to be faster as shown in Fig. 26 and Fig. 27.

\subsection{Strain-controlled fatigue tests on Cr-Mo steel}

A series of strain-controlled fatigue tests were conducted under similar conditions on 
samples machined from the Cr-Mo steel. Like the results of fatigue tests on the A533B steel, the magnetic properties of the $\mathrm{Cr}$-Mo steel also were found to change systematically with fatigue damage. Fig. 28 shows the effect of fatigue damage on the coercivity of Cr-Mo steel, Fig. 29 shows the remanence and Fig. 30 shows the hysteresis loss. Fig. 31 shows the effect of fatigue damage on the Barkhausen emissions.

The magnetic properties showed a similar evolution with fatigue as did the A533B steel, although Cr-Mo steel had a lower stable modulus and longer fatigue lifetime. The physical mechanism of fatigue in $\mathrm{Cr}$ Mo steel is considered to be the same as in the A533B steel. The redistribution of dislocations, the formation of slip bands, the initiation and propagation of fatigue cracks induced by the cyclic loading were responsible for the systematic changes in magnetic properties.

The fact that the magnetic properties of both A533B pressure vessel steel and Cr-Mo piping steel changed with fatigue damage systematically indicated the possibility of using magnetic techniques for the evaluation of progress of fatigue damage in steel in general.

\subsection{Modeling of strain-controlled fatigue}

In strain-controlled fatigue tests conducted in this study, the magnetic remanence was found to decrease with number of fatigue cycles in the same way as the mechanical modulus as shown previously in Figs. 9-11. This may indicate that the microstructural changes associated with fatigue crack initiation and propagation can affect the mechanical modulus and magnetic remanence together. In order to describe the dynamic changes in mechanical modulus and magnetic remanence respectively, the following four assumptions were made:

(1) During fatigue softening, the dislocation density decreases exponentially from an original value to a stable value for a given material and for a given applied strain.

(2) The change in modulus is proportional to the change in the dislocation density during fatigue softening.

(3) The modulus in the remaining area of the fatigue crack plane is the same as the modulus in the area before crack initiation.

(4) Compared with magnetic flux in the magnetic circuit which consists of the inspection head and fatigue specimen, the leakage of magnetic flux was negligible.

In addition, according to the numerical solution of the Jiles-Atherton model $\left[{ }^{14}\right]$, the change in remanence is proportional to the change in dislocation density in materials, such as A533B steel and Cr-Mo steel.

Fatigue crack propagation can be expressed in terms of total strain by a single power-law expression which extends from the elastic to the plastic strain region $\left[{ }^{15}\right]$ :

$$
\frac{d a}{d n}=C \varepsilon^{m}
$$

Based on the above assumptions and taking into account experimental results, a pair of half empirical model equations were developed in this study, which describe the dynamic change in the measured magnetic properties and measured mechanical modulus during strain-controlled fatigue.

$$
\begin{gathered}
Y_{m}=\left(Y_{i n i}-Y_{0}\right) e^{-\frac{n}{R}}+Y_{0}-Y_{0} Q\left(n-n_{0}\right)^{2} \\
B_{r m}=\left(B_{r_{i n i}}-B_{r 0}\right) e^{-\frac{n}{R}}+B_{r 0}-B_{r 0} Q\left(n-n_{0}\right)^{2}
\end{gathered}
$$

Where the $Y_{\text {ini }}$ and $B r_{\text {ini }}$ are initial mechanical modulus and initial remanence respectively, $Y_{0}$ and $B r_{0}$ are the stable mechanical modulus and remanence respectively and $Q$ is a parameter which describes the propagation rate of the fatigue crack.

The models describe experimental results well. Fig. 32 and Fig. 33 show the agreement between the model and measurement of the mechanical modulus. Fig. 34 and Fig. 35 show the agreement between the model and measurement of the 
measured remanence throughout the fatigue lifetime. The first terms of the above two model equations decay to zero after several hundred cycles, thereafter the models also showed the relationship between measured modulus and measured remanence, which was observed in strain-controlled fatigue tests as shown previously in Fig. 18 and Fig. 19.

$$
Y_{m}=\frac{Y_{0}}{B_{r 0}} B_{r m}
$$

The above simple mathematical equations enable us to describe the evolution of the behavior of the material during its fatigue lifetime and to evaluate fatigue damage through remanence measurements.

\subsection{Relationship between fatigue lifetime and magnetic properties}

A relationship between the measured baseline magnetic coercivity and the measured fatigue lifetime was observed on samples machined from the same A533B steel block as shown in Fig. 36. Since these specimens had the same chemical compositions, the difference in baseline magnetic properties was attributed to the accumulated residual stress resulting from service aging, machining and polishing of the samples. The residual stress affects the fatigue behavior of the samples as well as their magnetic properties.

Since both baseline magnetic properties and fatigue lifetime are related to the microstructures in a complicated way, an exact quantitative theoretical relationship between baseline coercivity and fatigue lifetime is not yet clear. In general, specimens with larger baseline coercivity had shorter fatigue lifetimes. Within different groups of specimens, those with larger average baseline coercivity also had shorter average fatigue lifetime. Therefore in broad terms it can be said that low coercivity corresponds to large fatigue lifetime. Considering however that fatigue lifetime can be affected by many factors, and also that surface conditions can significantly alter the fatigue lifetime, deviation from this simple relationship from sample to sample was expected and was in fact observed in this study. 


\section{CONCLUSIONS}

The magnetic properties of steels are related to their mechanical properties through the microstructure. The magnetic properties were found to change with fatigue damage systematically in both A533B steels and CrMo steel, under both strain-controlled and load-controlled fatigue modes in both the low-cycle and high-cycle regions. A relationship between magnetic and mechanical properties was observed. A linear relationship between the mechanical modulus and magnetic remanence under strain-controlled fatigue conditions was observed in this study, and from this a model was developed which describes the evolution of the properties of these materials during fatigue.

The fact that the magnetic properties of both
A533B pressure vessel steel and Cr-Mo steel under different fatigue conditions changed systematically and significantly with fatigue damage demonstrated the viability of magnetic techniques for the non-destructive evaluation of fatigue damage in these steels. Together with the point-to-point magnetic images, which revealed localized inhomogeneities and defects, the results of this study also exhibited the versatility of these magnetic methods as a new technology for materials evaluation. These techniques have been incorporated with two magnetic measuring instruments, the Magnescope and the Magneprobe, which can be used for insitu nondestructive evaluation of steel structures and components, such as are currently being used in nuclear installations. 



\section{REFERENCES}

1. D.C. Jiles, S.B. Biner, M.R. Govindaraju and Z.J. Chen. "Applications of a new magnetic monitoring technique to in situ evaluation of fatigue damage in ferrous components of nuclear primary systems". Final contract report, Nuclear Regulatory Commission, grant number NRC-04-91-098, (December 1993).

2. A.R.Eichman et al., "New procedures for in situ measurement of the magnetic properties of materials; applications of the Magnescope", IEEE Trans. Mag. 28, (5), (1992), 2462.

3. A.P.Parakka, and D.C. Jiles, " Magneprobe: a portable system for detection and characterization of Barkhausen signals for nondestructive testing of ferromagnet material", Journal of Magnetism and Magnetic Materials, (1841), (1995), 140-144.

4. D.C. Jiles, "Review of magnetic methods for NDE", NDT International, 21 (1988), 311.

5. W.J. Harris, "The significance of fatigue", Engineering Design Guides, 14 (Design Council, Oxford University Press, 1976).

6. M.S.C. Bose, "A study of fatigue in ferromagnetic materials using magnetic hysteresis technique", $N D T$ International, 19, (2), (1986), 83.

7. M.K. Devine, D.C.Jiles, and S. Hariharan, "Effects of cyclic stress on the magnetic hysteresis parameters of polycrystalline iron" Journal of Magnetism and Magnetic Materials, 104, (1992), 377.
8. Z.J. Chen, D.C.Jiles, and J.Kameda, " Estimation of fatigue exposure from magnetic coercivity", J. appl. Phys., 75(10), (1994).

8. D.L. Atherton and D.C. Jiles. NDT International 19, 15, (1986).

10. M.K. Devine, D.A. Kaminski, L.B. Sipahi and D.C. Jiles. J. Mater. Eng. \& Perf. 1, 249, (1992).

11. D.C. Jiles, R. Kern and W.A. Theiner. Nondestructive Testing and Evaluation 10, 17, (1993).

12. L.B. Sipahi and D.C. Jiles. Nondestructive Testing and Evaluation, 183, (1992).

13. D.C. Jiles and L. Suominen. "Effects of surface stress on computer simulation of Barkhausen effect emissions: model predictions and comparison with $\mathrm{X}$ ray diffraction studies", IEEE Trans. Mag. 30, 4924, 1994.

14. D.C. Jiles and D.L. Atherton, "Theory of Ferromagnetic Hysteresis", Journal of Magnetism and Magnetic Materials, 61, (1986), 48.

15. T.W. Crooker and E.A. Lange, op. cit. p.94 


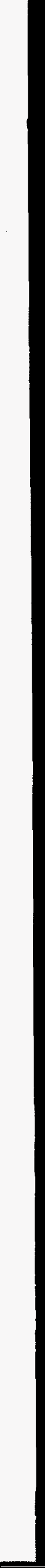




\section{Appendix A \\ Tables and Figures}

Table 1 Chemical compositions of steels involved in this project

\begin{tabular}{|c|c|c|c|c|c|c|c|}
\hline & $\mathrm{C}$ & $\mathrm{Cr}$ & $\mathrm{Mo}$ & $\mathrm{Si}$ & $\mathrm{Ni}$ & $\mathrm{Mn}$ & $\mathrm{Fe}$ \\
\hline 1st A533B & 0.223 & 0.06 & 0.50 & 0.22 & 0.56 & 1.45 & Bal. \\
\hline 2nd A533B & 0.234 & 0.05 & 0.55 & 0.21 & 0.57 & 1.32 & Bal. \\
\hline Cr-Mo Steel & 0.0896 & 2.00 & 1.03 & 0.37 & 0.13 & 0.50 & Bal. \\
\hline
\end{tabular}

Table 2 The effect of microstructures on magnetic properties, stable modulus, hardness and fatigue lifetime

\begin{tabular}{|c|c|c|c|c|c|c|}
\hline & $\begin{array}{c}\text { Grain } \\
\text { size }\end{array}$ & $\begin{array}{c}\text { Baseline } \\
\mathrm{Hc}\end{array}$ & $\begin{array}{c}\mathrm{MBE} \\
(\mathrm{rms})\end{array}$ & $\begin{array}{c}\text { Stable } \\
\text { Load }\end{array}$ & $\begin{array}{c}\text { Rockwell } \\
\text { Hardness }\end{array}$ & $\begin{array}{c}\text { Fatigue } \\
\text { Lifetim } \\
\mathrm{e}\end{array}$ \\
\hline 1st A533B Steel & $5 \mu \mathrm{m}$ & $7.4 \mathrm{Oe}$ & $0.22 \mathrm{~V}$ & $9.8 \mathrm{KN}$ & $\mathrm{B} 85$ & 15000 \\
\hline 2nd A533B steel & $9 \mu \mathrm{m}$ & $8.6 \mathrm{Oe}$ & $0.22 \mathrm{~V}$ & $12.3 \mathrm{KN}$ & $\mathrm{B} 91$ & 3800 \\
\hline Cr-Mo steel & $13 \mu \mathrm{m}$ & $4.9 \mathrm{Oe}$ & $0.25 \mathrm{~V}$ & $6.4 \mathrm{KN}$ & $\mathrm{B} 60$ & 16200 \\
\hline
\end{tabular}


Table 3 The baseline magnetic properties of two A533B steels ( $\mathrm{Hc}, \mathrm{Br}$, Loss and Vrms).

\begin{tabular}{|c|c|c|c|c|c|c|c|}
\hline & \multicolumn{3}{|c|}{ Magnescope } & \multicolumn{3}{c|}{ Hysteresisgraph } & Magneprobe \\
\hline Sample & $\begin{array}{c}\mathrm{Hc} \\
(\mathrm{Oe})\end{array}$ & $\begin{array}{c}\mathrm{Br} \\
(\mathrm{Gauss})\end{array}$ & $\begin{array}{c}\text { Loss } \\
(\mathrm{ergs} / \mathrm{cc})\end{array}$ & $\begin{array}{c}\mathrm{Hc} \\
(\mathrm{Oe})\end{array}$ & $\begin{array}{c}\mathrm{Br} \\
(\text { Gauss })\end{array}$ & $\begin{array}{c}\text { Loss } \\
(\mathrm{ergs} / \mathrm{cc})\end{array}$ & $\begin{array}{c}\text { Vrms } \\
(\text { Volts })\end{array}$ \\
\hline $\mathrm{A} 1$ & 7.360 & 3909 & 10299 & 6.624 & 2362 & 10618 & 0.222 \\
\hline A2 & 8.103 & 3261 & 11242 & 7.726 & 2380 & 11559 & 0.219 \\
\hline A3 & 8.913 & 3061 & 12777 & 8.502 & 2410 & 12982 & 0.194 \\
\hline A4 & 6.930 & 4016 & 10251 & 6.228 & 2387 & 10485 & 0.228 \\
\hline A5 & 6.833 & 4023 & 10157 & 6.166 & 2392 & 10696 & 0.245 \\
\hline A6 & 7.223 & 3977 & 10928 & 6.648 & 2566 & 11155 & 0.260 \\
\hline Group A & $\mathbf{7 . 5 6 1}$ & $\mathbf{3 7 0 8}$ & $\mathbf{1 0 9 4 3}$ & $\mathbf{6 . 9 8 2}$ & $\mathbf{2 4 1 6}$ & $\mathbf{1 1 2 4 9}$ & $\mathbf{0 . 2 2 8}$ \\
\hline & & & & & & & \\
\hline B1 & 8.047 & 3482 & 11194 & 7.380 & 2504 & 11559 & 0.212 \\
\hline B2 & 6.740 & 3909 & 9863 & 6.134 & 2378 & 10446 & 0.211 \\
\hline B3 & 6.900 & 3900 & 9885 & 6.112 & 2416 & 10290 & 0.219 \\
\hline B4 & 8.063 & 3390 & 11273 & 7.396 & 2408 & 11568 & 0.202 \\
\hline B5 & 6.800 & 3863 & 10051 & 6.188 & 2440 & 10741 & 0.246 \\
\hline B6 & 6.797 & 3597 & 9261 & 6.094 & 2449 & 9826 & 0.220 \\
\hline Group B & 7.224 & $\mathbf{3 6 9 0}$ & $\mathbf{1 0 2 5 4}$ & $\mathbf{6 . 5 5 1}$ & $\mathbf{2 4 3 3}$ & $\mathbf{1 0 7 3 8}$ & $\mathbf{0 . 2 1 8}$ \\
\hline & & & & & & & \\
\hline CA & 10.08 & 3308 & 13569 & 9.286 & 2605 & 13787 & 0.225 \\
\hline CB & 9.416 & 3129 & 13336 & 9.024 & 2591 & 13980 & 0.235 \\
\hline CC & 8.758 & 3482 & 12162 & 8.182 & 2486 & 13084 & 0.221 \\
\hline CD & 8.302 & 3711 & 12004 & 8.008 & 2721 & 13052 & 0.225 \\
\hline CE & 7.738 & 3576 & 11330 & 7.332 & 2495 & 12578 & 0.195 \\
\hline Group C & $\mathbf{8 . 8 5 9}$ & $\mathbf{3 4 4 1}$ & $\mathbf{1 2 4 8 0}$ & $\mathbf{8 . 3 6 6}$ & $\mathbf{2 5 8 0}$ & $\mathbf{1 3 2 9 6}$ & $\mathbf{0 . 2 2 0}$ \\
\hline & & & & & & & \\
\hline
\end{tabular}


Table 4 The baseline magnetic properties of the Cr-Mo steels ( $\mathrm{Hc}$, Br, Loss and Vrms).

\begin{tabular}{|c|c|c|c|c|c|c|c|}
\hline & \multicolumn{3}{|c|}{ Magnescope } & \multicolumn{3}{c|}{ Hysteresisgraph } & Magneprobe \\
\hline Sample & $\begin{array}{c}\mathrm{Hc} \\
(\mathrm{Oe})\end{array}$ & $\begin{array}{c}\mathrm{Br} \\
(\mathrm{Gauss})\end{array}$ & $\begin{array}{c}\text { Loss } \\
(\mathrm{ergs} / \mathrm{cc})\end{array}$ & $\begin{array}{c}\mathrm{Hc} \\
(\mathrm{Oe})\end{array}$ & $\begin{array}{c}\mathrm{Br} \\
(\mathrm{Gauss})\end{array}$ & $\begin{array}{c}\text { Loss } \\
(\mathrm{ergs} / \mathrm{cc})\end{array}$ & $\begin{array}{c}\text { Vrms } \\
(\text { Volts) }\end{array}$ \\
\hline E1 & 5.05 & 2591 & 6564 & 4.513 & 1629 & 7055 & 0.246 \\
\hline E2 & 4.96 & 2390 & 6459 & 4.347 & 1617 & 6884 & 0.242 \\
\hline E3 & 4.82 & 2284 & 6719 & 4.470 & 1669 & 7335 & 0.259 \\
\hline E4 & 5.00 & 2422 & 6434 & 4.487 & 1673 & 7181 & 0.251 \\
\hline E5 & 5.01 & 2586 & 6590 & 4.440 & 1633 & 6994 & 0.244 \\
\hline E6 & 4.95 & 2866 & 6462 & 4.340 & 1787 & 7019 & 0.255 \\
\hline E7 & 4.91 & 2868 & 6611 & 4.353 & 1707 & 6902 & 0.252 \\
\hline E8 & 4.88 & 2572 & 6266 & 4.367 & 1731 & 6996 & 0.245 \\
\hline E9 & 4.90 & 2608 & 6473 & 4.440 & 1709 & 7116 & 0.243 \\
\hline Group E & $\mathbf{4 . 9 4}$ & $\mathbf{2 5 7 6}$ & $\mathbf{6 5 0 9}$ & $\mathbf{4 . 4 2}$ & 1684 & $\mathbf{7 0 5 3}$ & $\mathbf{0 . 2 4 9}$ \\
\hline
\end{tabular}




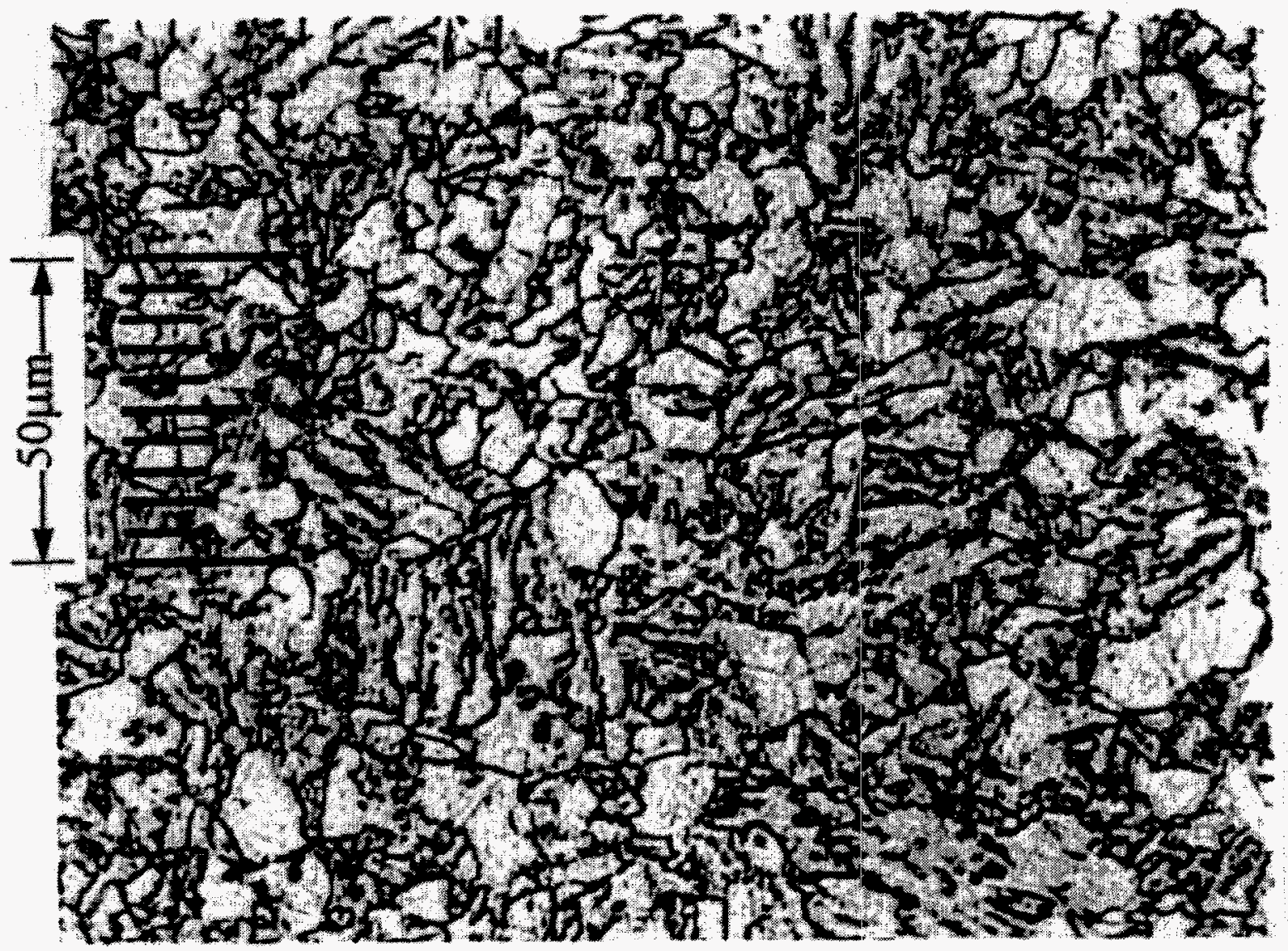

Fig. 1 Micrograph of the first A533B steel. 


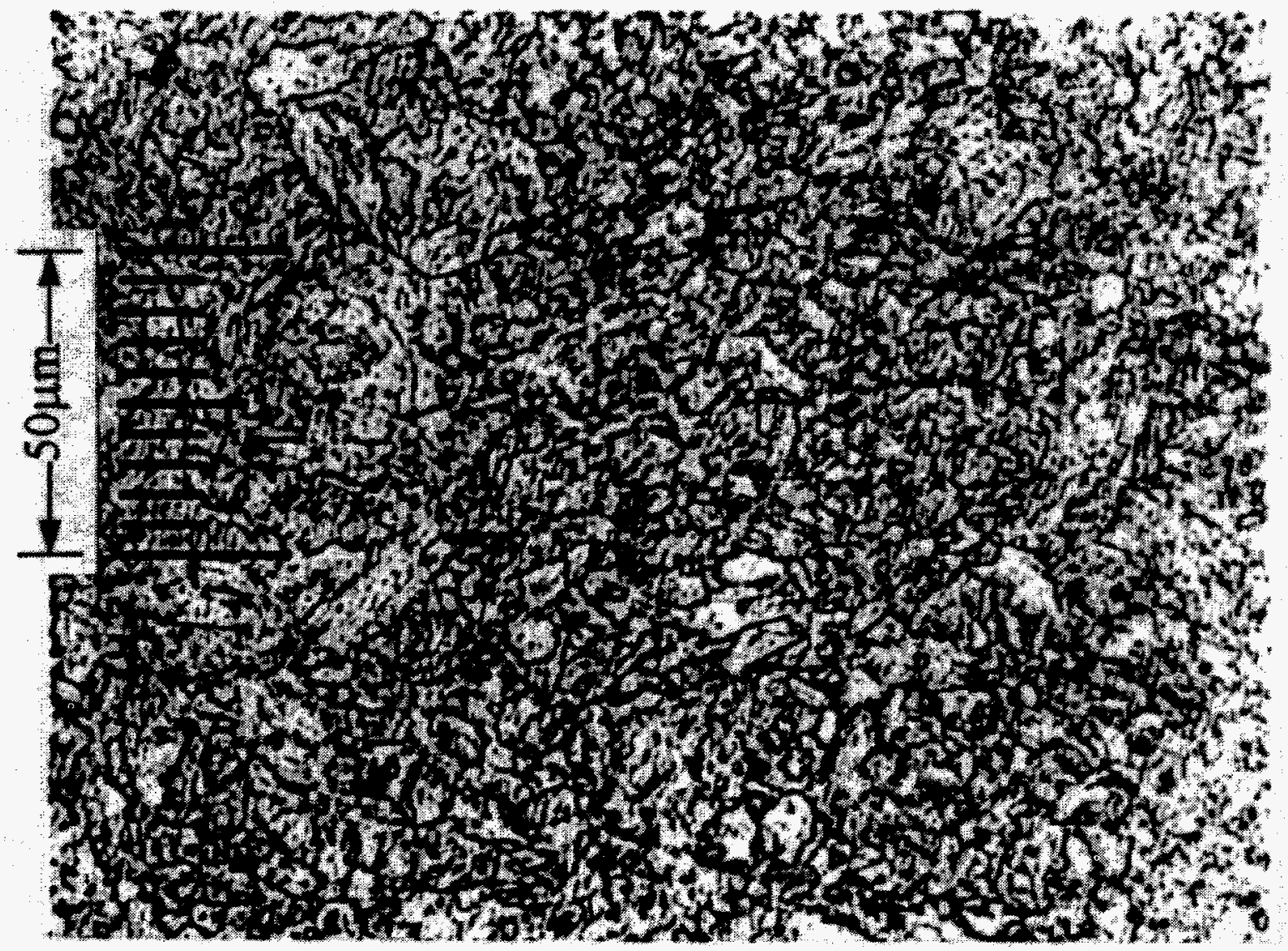

Fig. 2 Micrograph of the second A533B steel. 


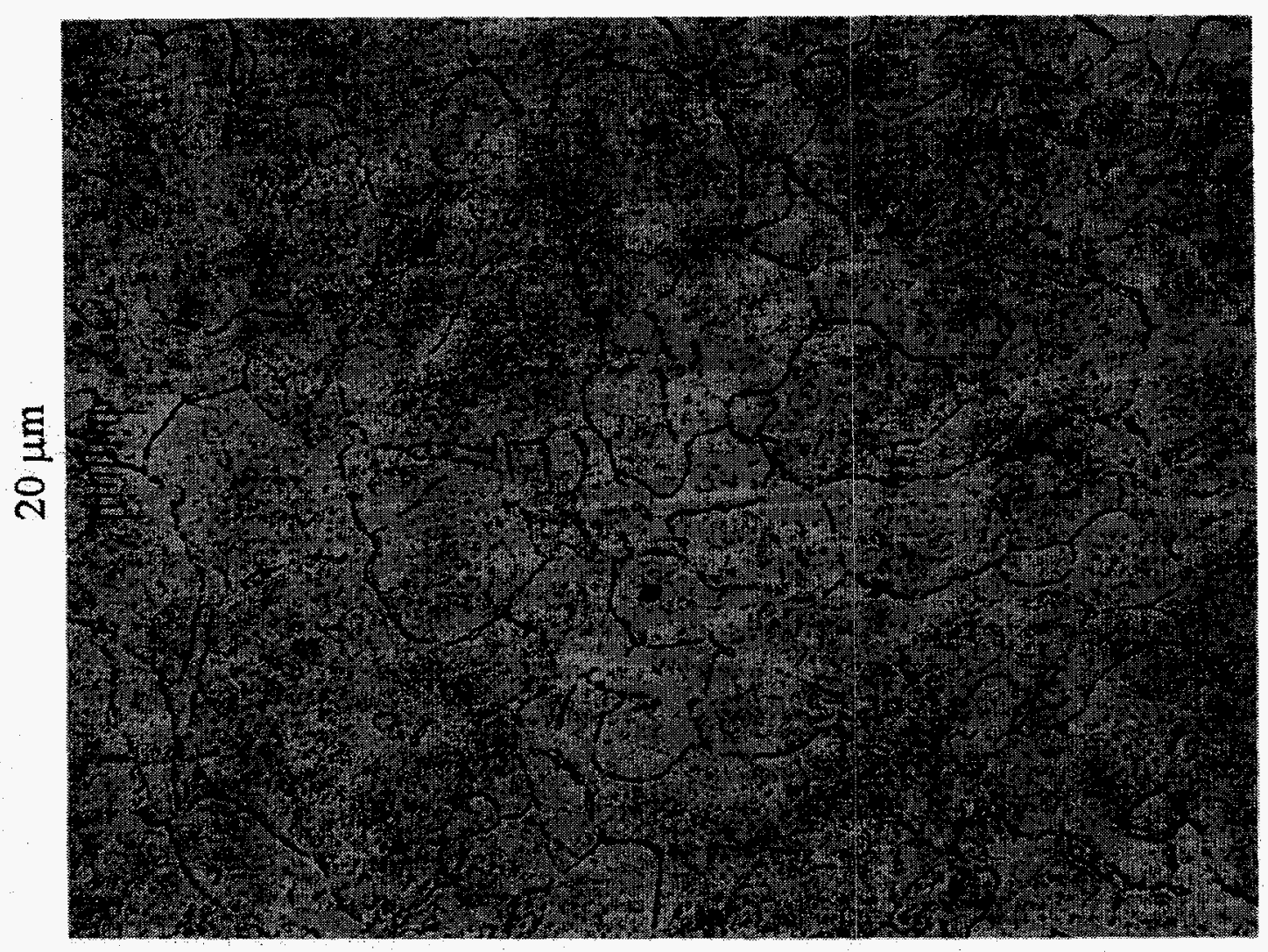

Fig. 3 Micrograph of the Cr-Mo steel. 


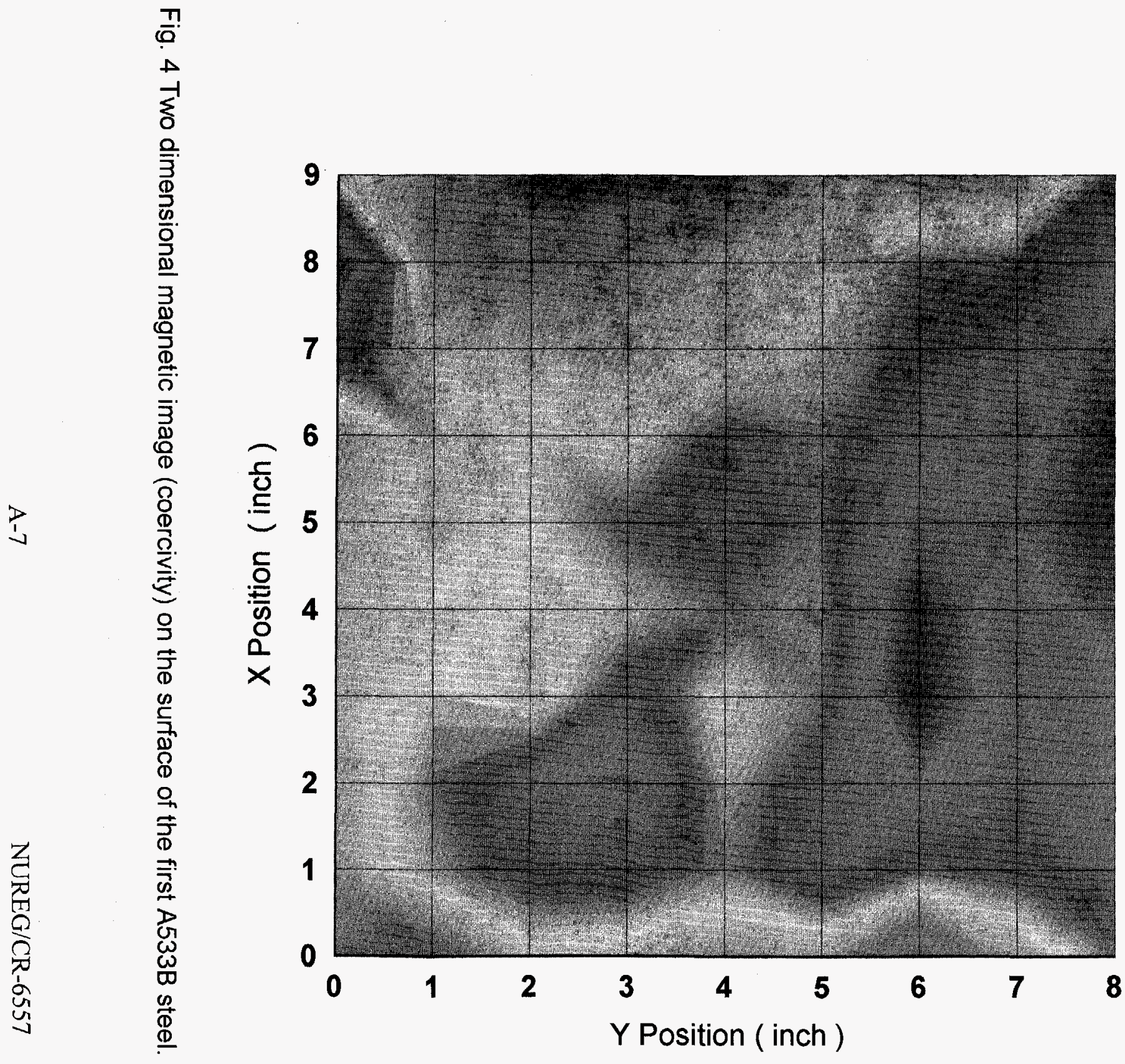

Coercivity (Oe)

$5.41+$

5.33 to 5.41

5.25 to 5.33

5.16 to 5.25

5.08 to 5.16

5.00 to 5.08

4.92 to 5.00

4.84 to 4.92

4.76 to 4.84

4.67 to 4.76

4.59 to 4.67

4.51 to 4.59 
Coercivity ( $\mathrm{Oe}$ )

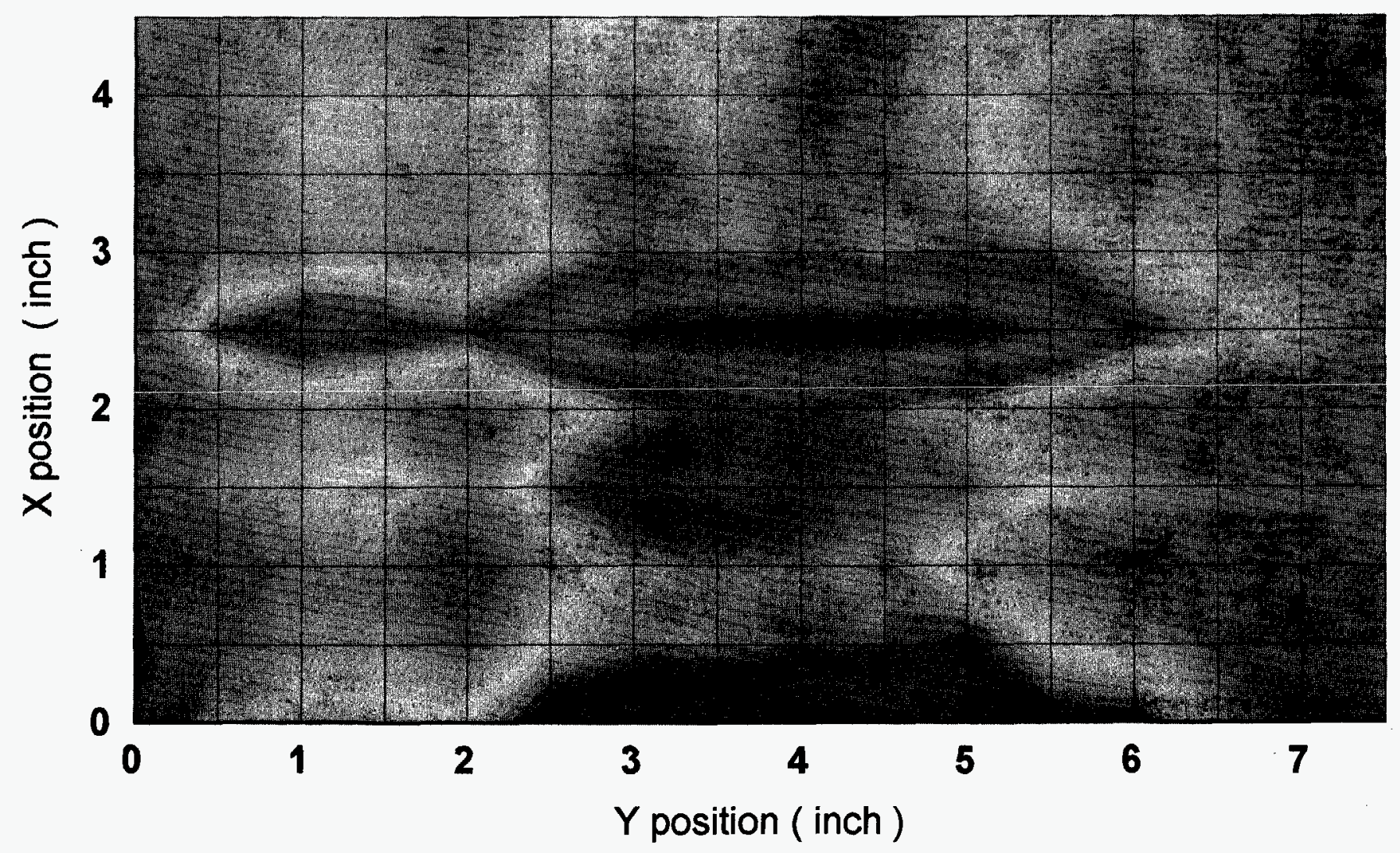

6.19 to 6.34

6.03 to 6.19

5.88 to 6.03

5.72 to 5.88

5.57 to 5.72

5.41 to 5.57

5.25 to 5.41

5.10 to 5.25

4.94 to 5.10

4.79 to 4.94

4.63 to 4.79 


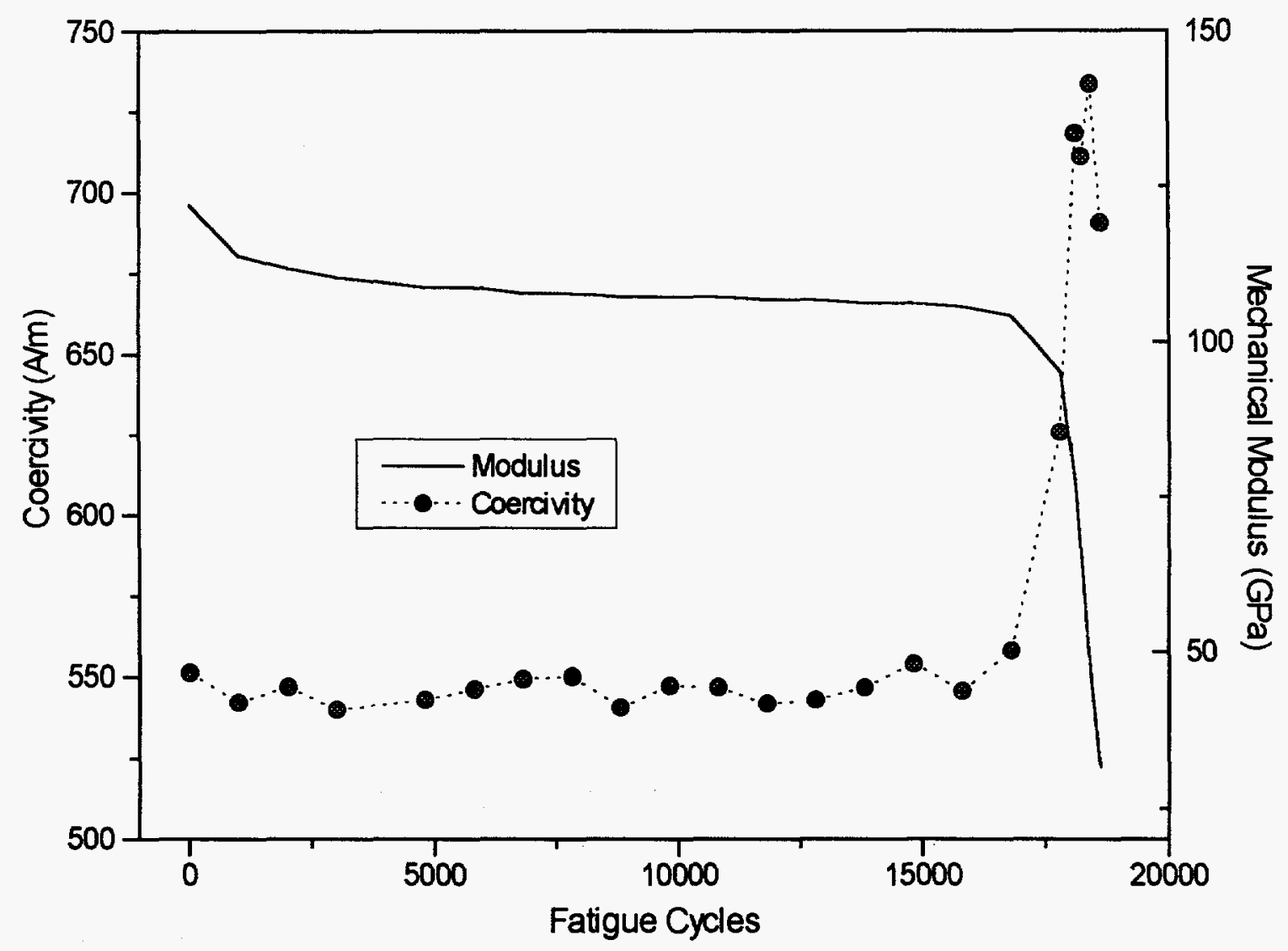

Fig. 6 The effect of strain-controlled fatigue on coercivity in one specimen cutting from first A533B steel block along rolling direction ( group A ) 


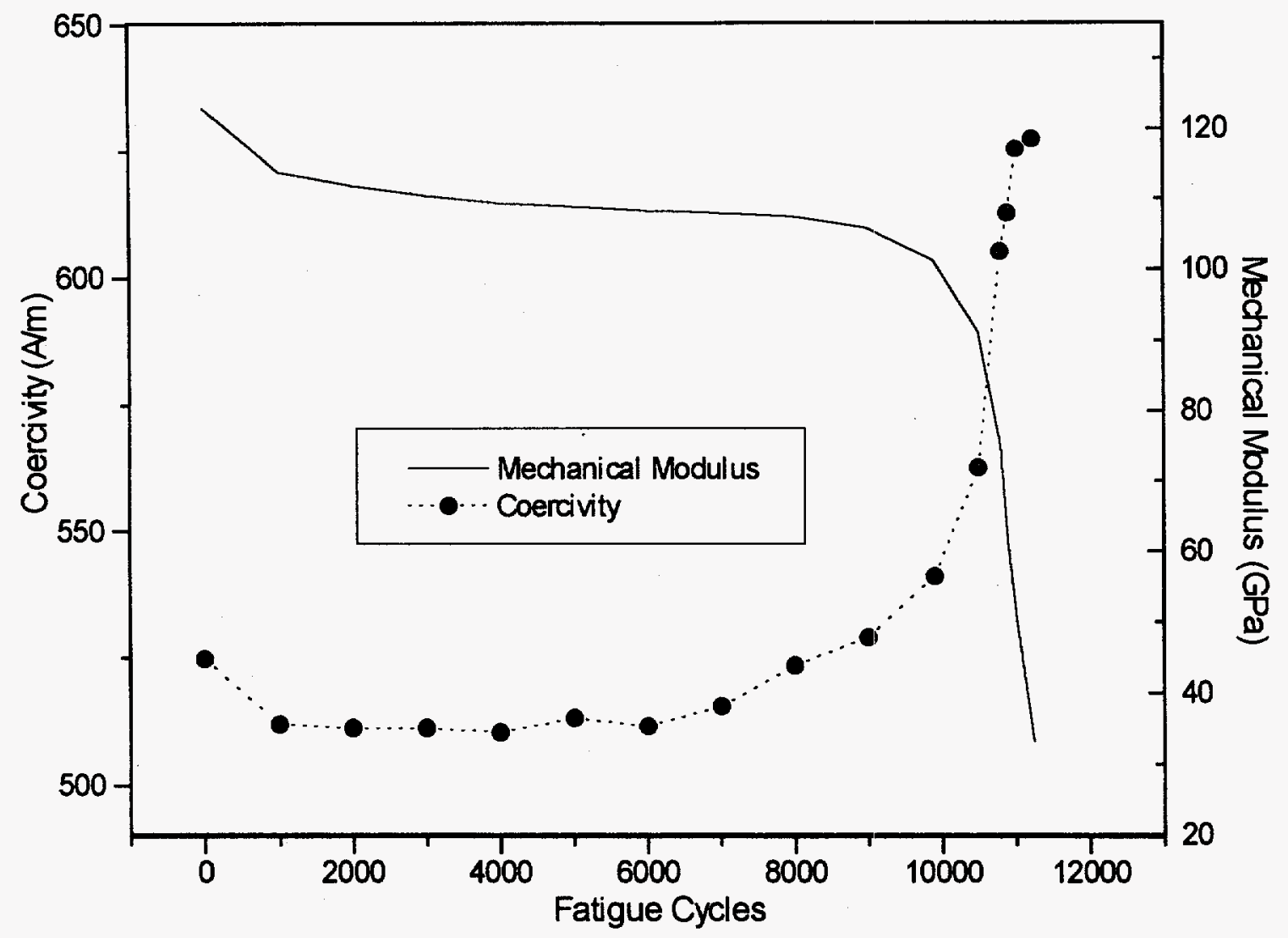

Fig. 7 The effect of strain-controlled fatigue on coercivity in one specimen cutting from first A533B steel block normal to rolling direction ( group B ) 


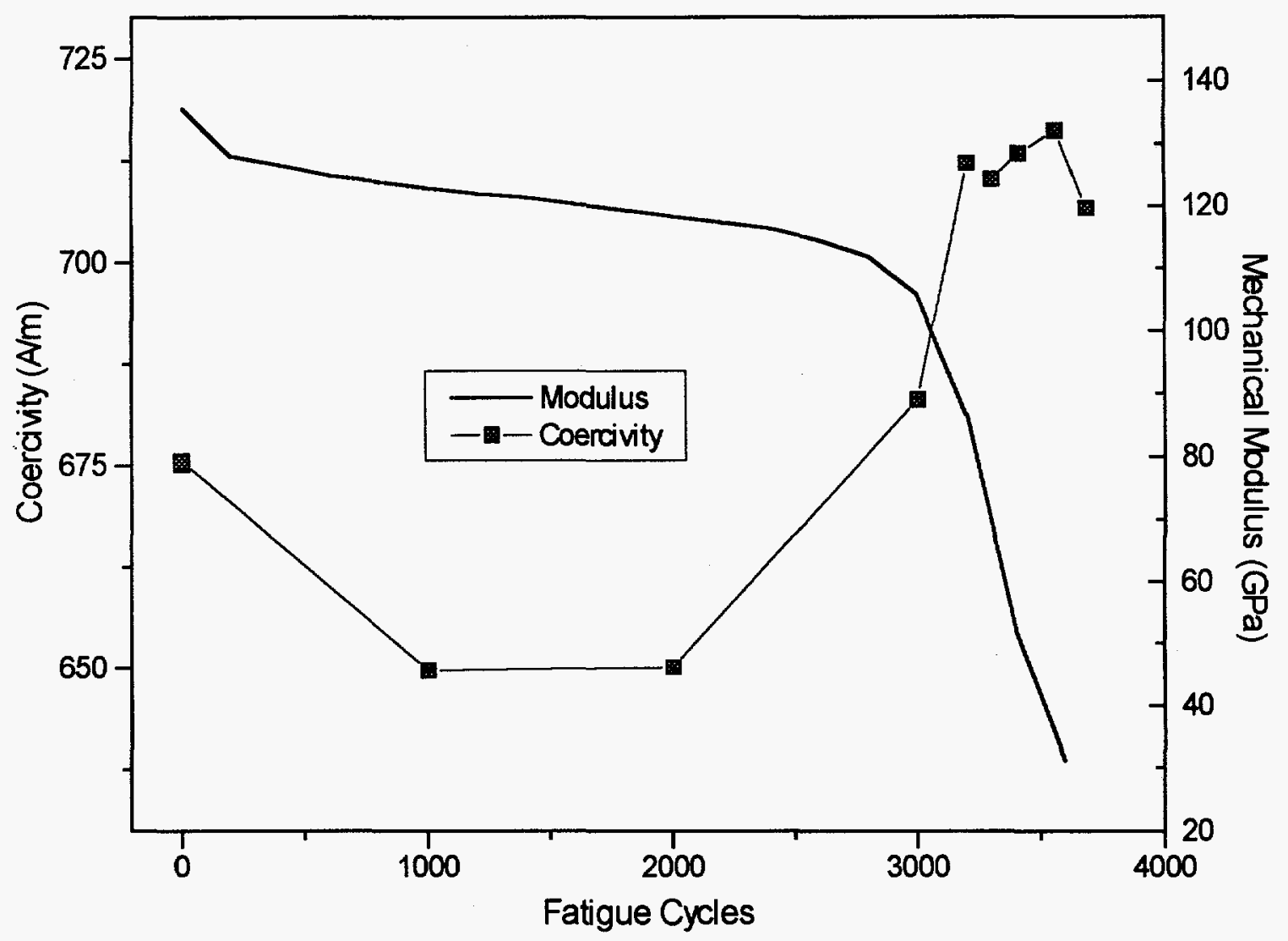

Fig. 8 The effect of strain-controlled fatigue on coercivity in one specimen machined from the second A533B steel (Group C). 


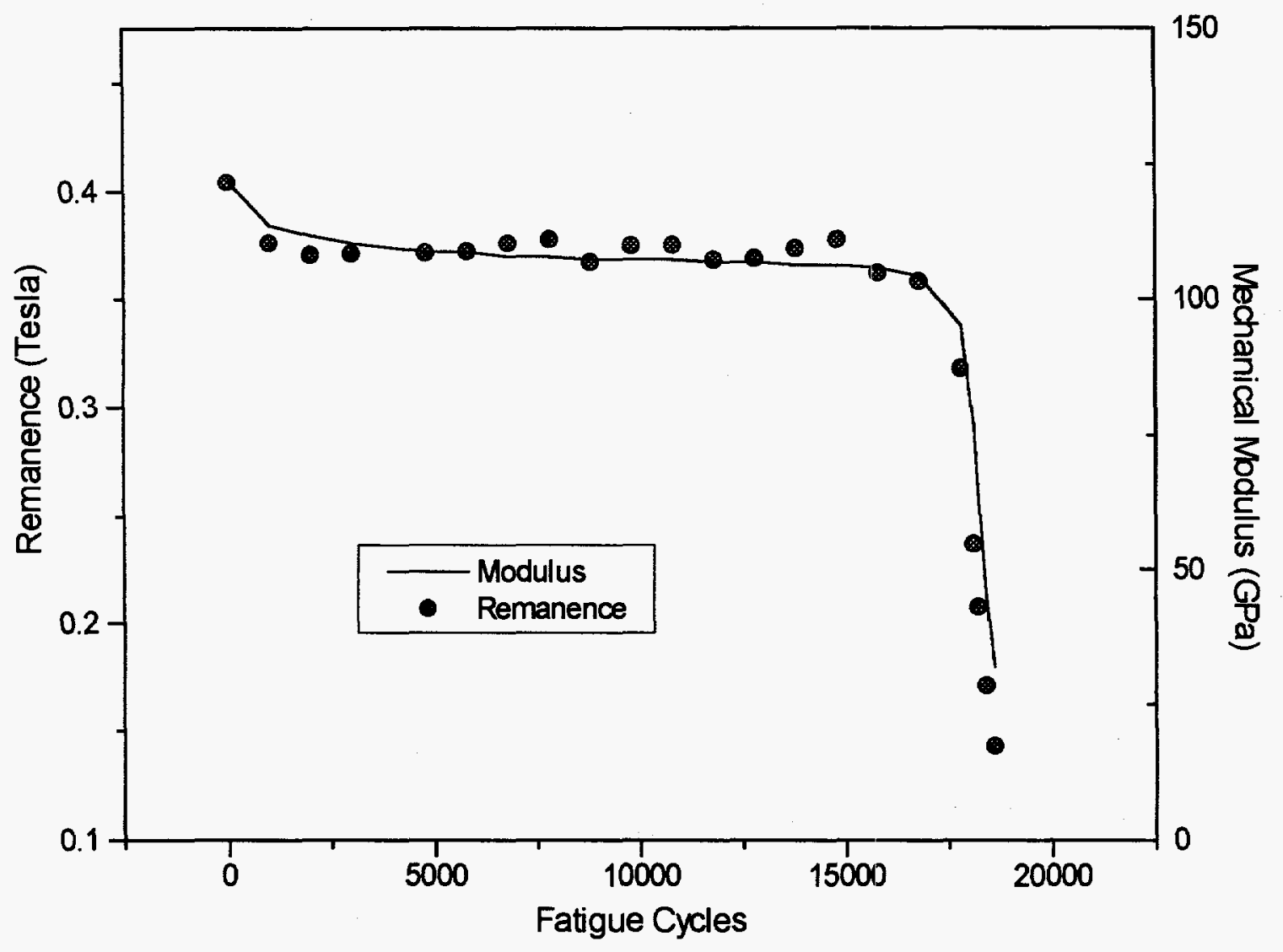

Fig. 9 The effect of strain-controlled fatigue on remanence in one specimen cutting from first A533B steel block along rolling direction ( group A ). 


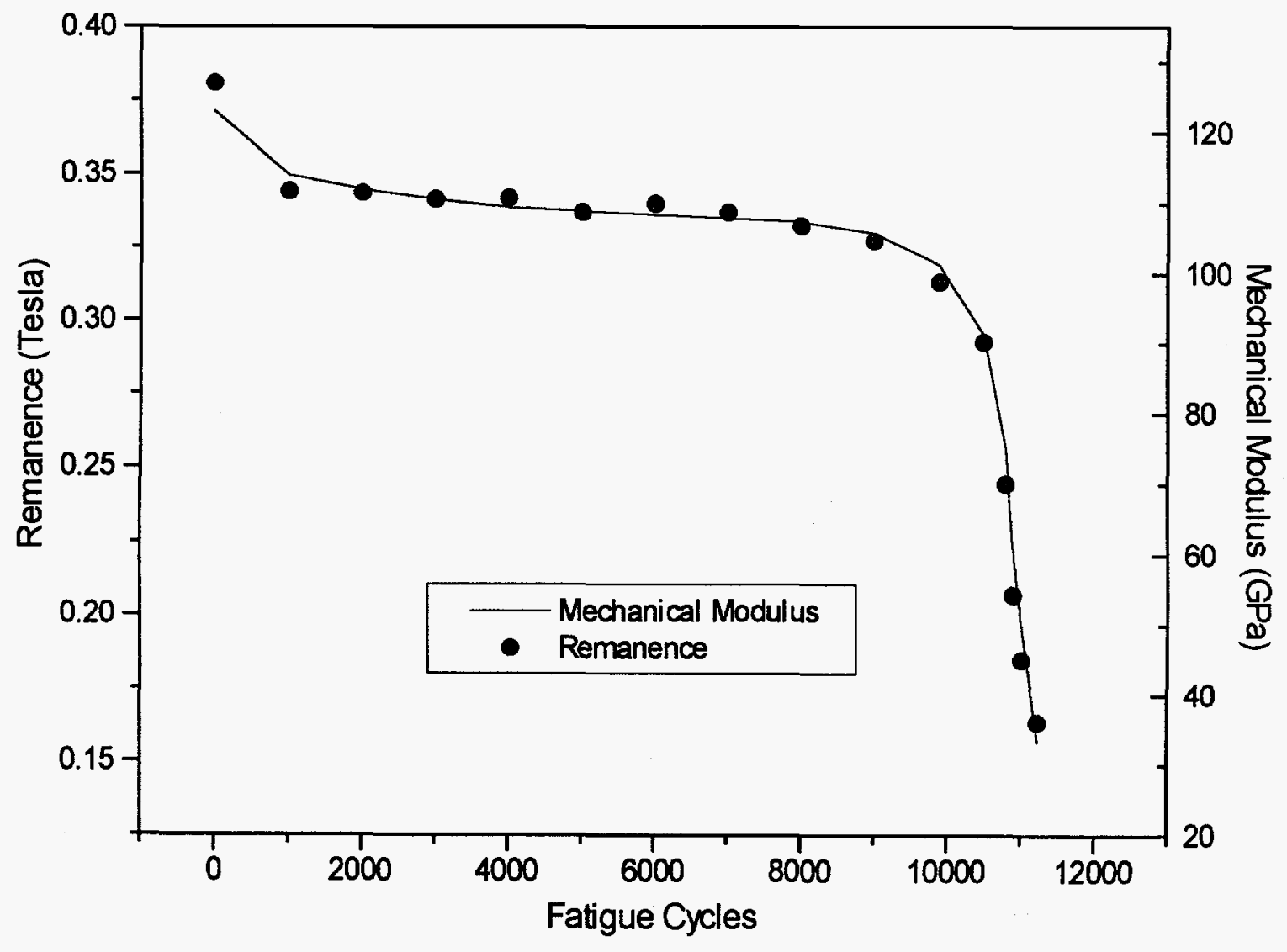

Fig. 10 The effect of strain-controlled fatigue on remanence in one specimen cutting from first A533B steel block normal to rolling direction (group B ). 


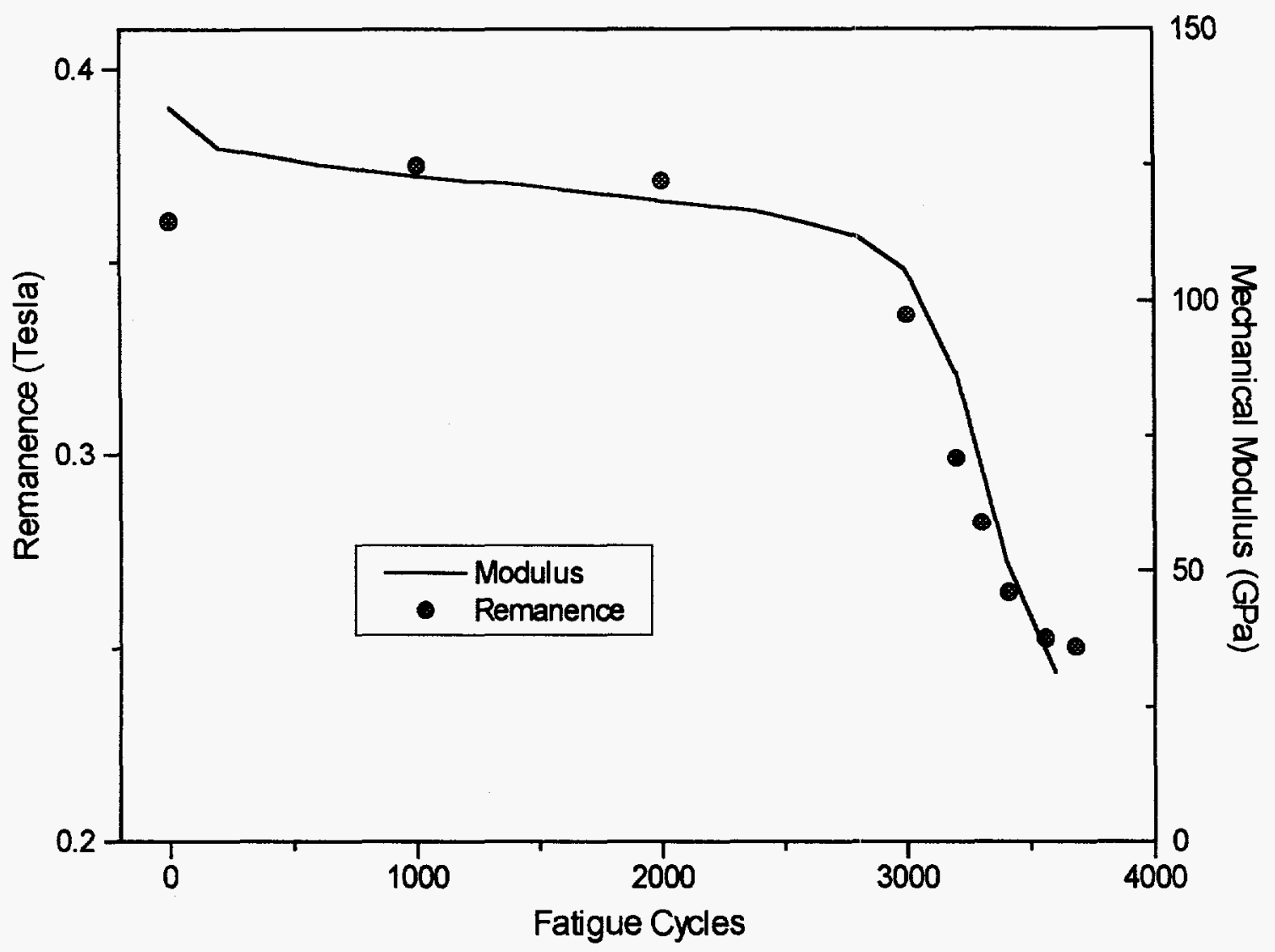

Fig. 11 The effect of strain-controlled fatigue on remanence in one specimen machined from the second A533B steel (Group C). 


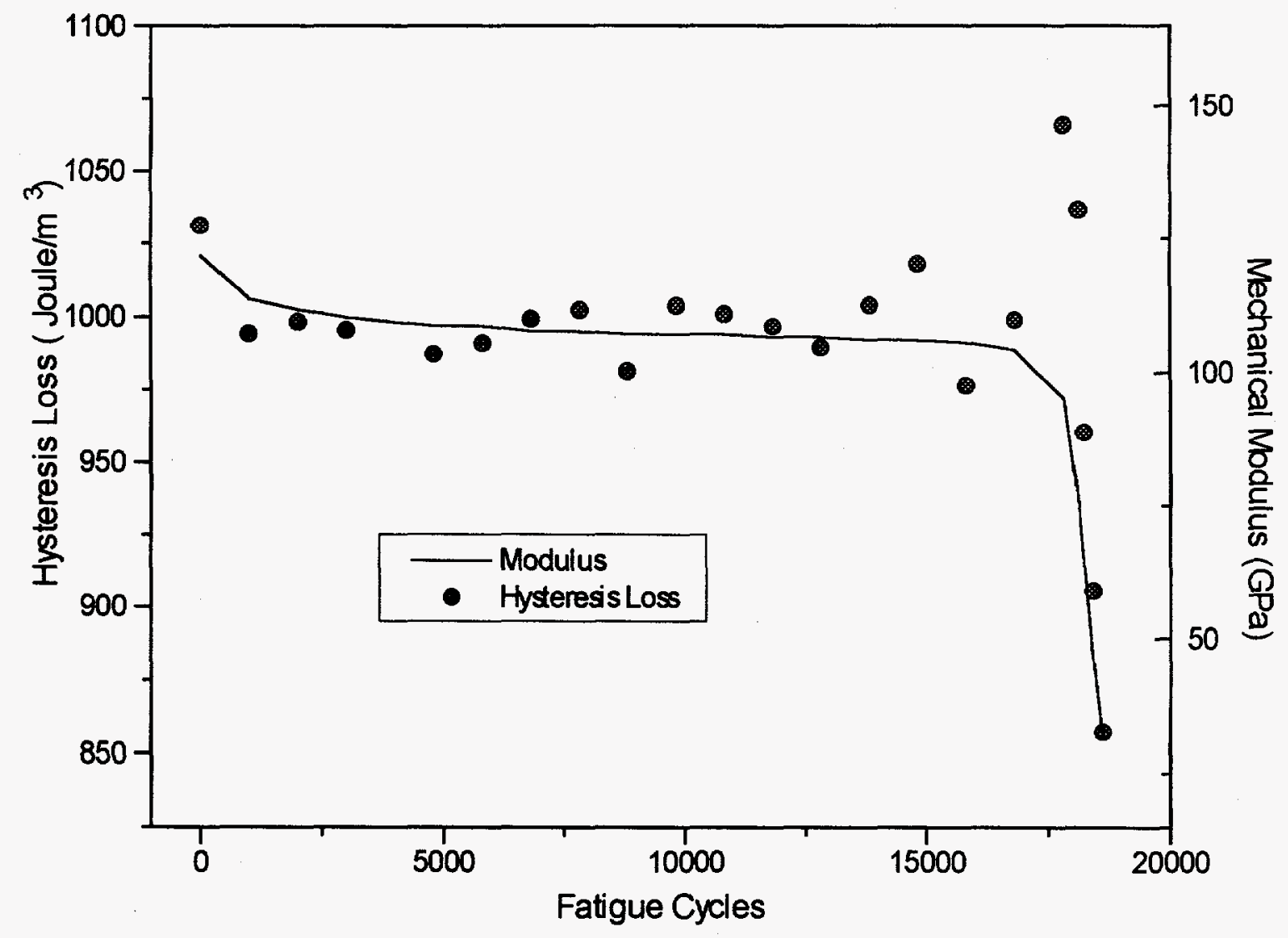

Fig. 12 The effect of strain-controlled fatigue on hysteresis loss in one specimen cut from first A533B steel block along rolling direction (group A ). 


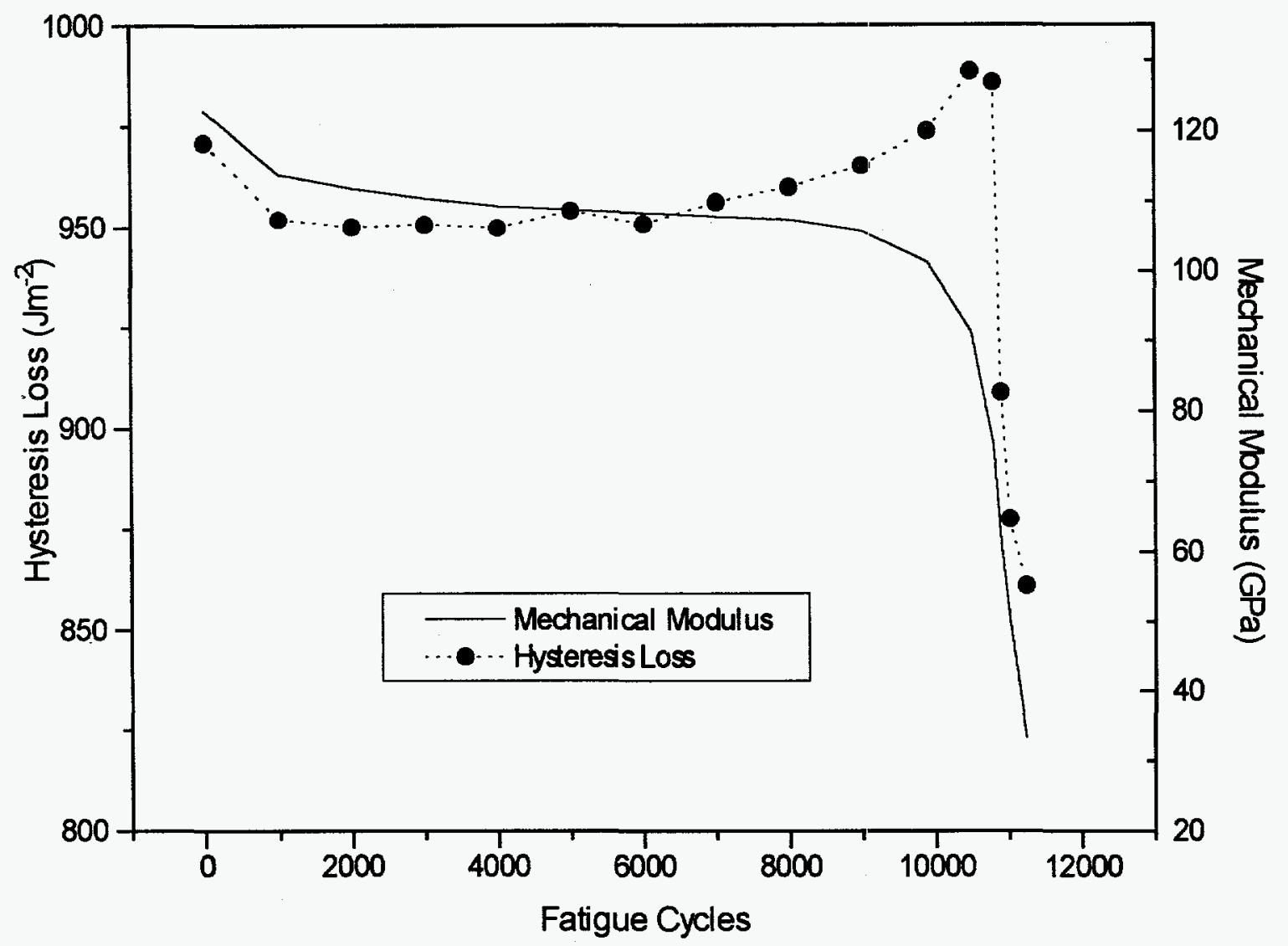

Fig. 13 The effect of strain-controlled fatigue on hysteresis loss in one specimen cut from first A533B steel block normal to rolling direction (group B ). 


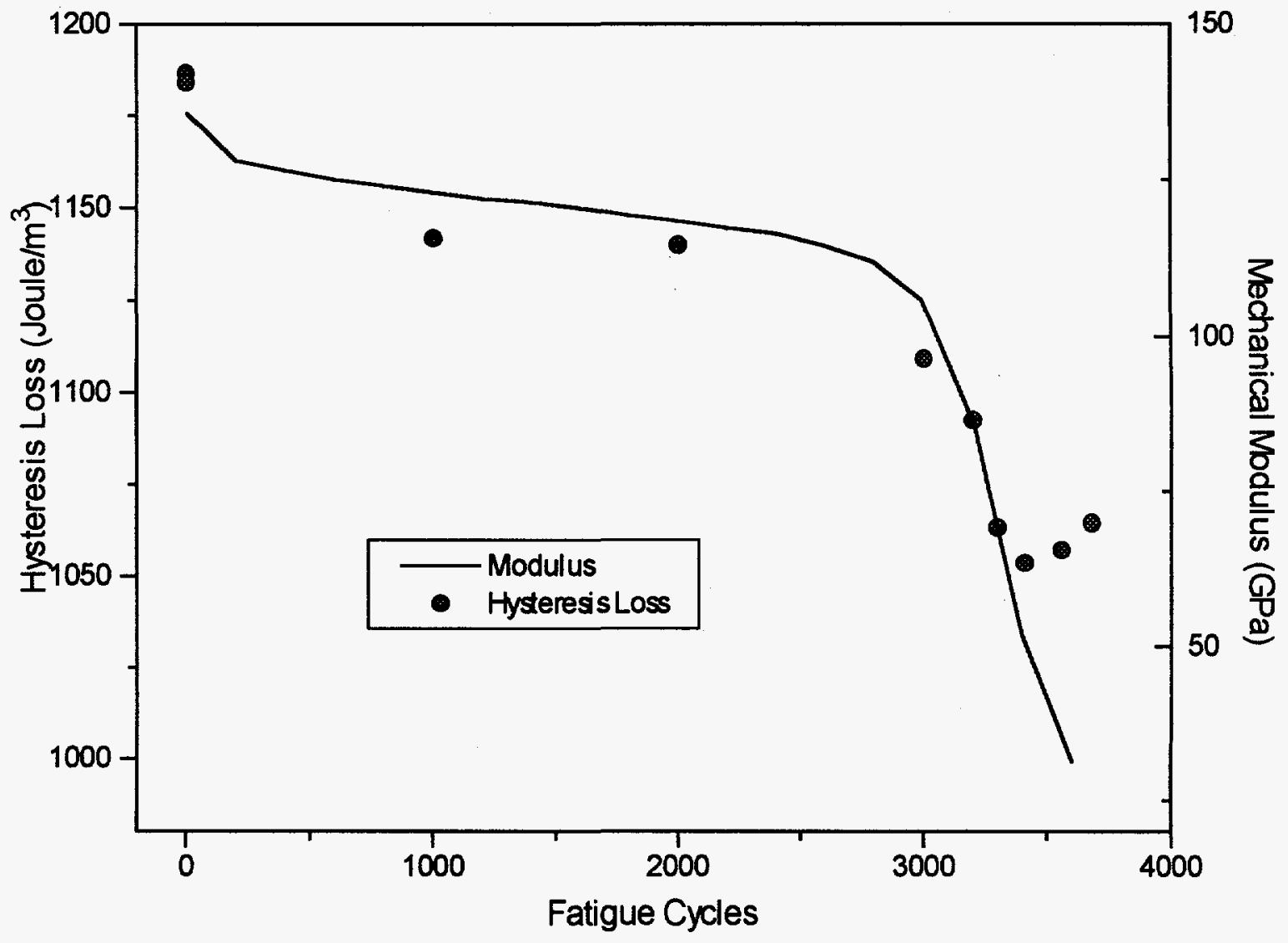

Fig. 14 The effect of strain-controlled fatigue on hysteresis loss in one specimen machined from the second A533B steel (Group C). 


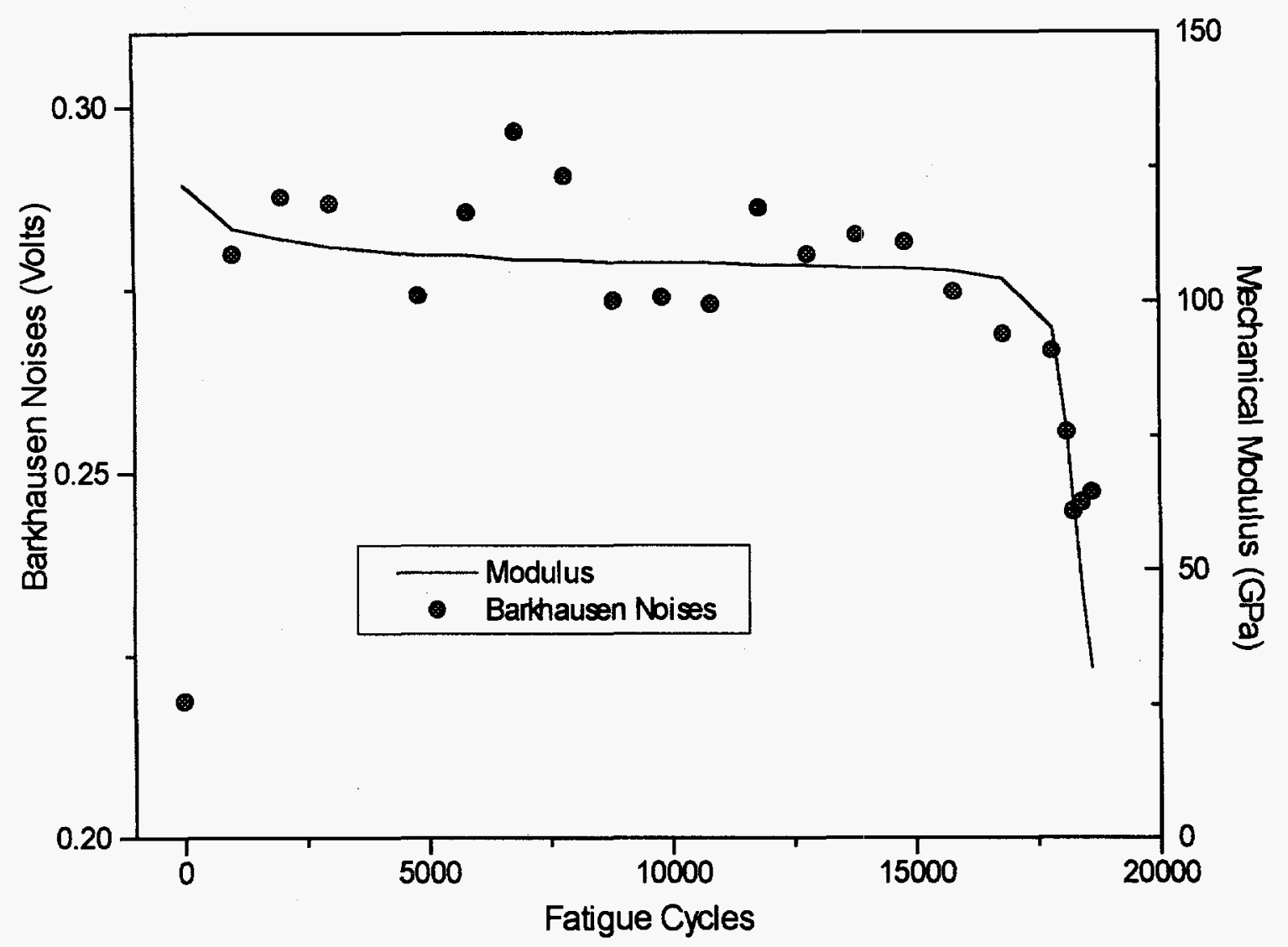

Fig. 15 The effect of strain-controlled fatigue on Barkhausen emissions in one specimen machined from the first A533B steel block along rolling direction (group A). 


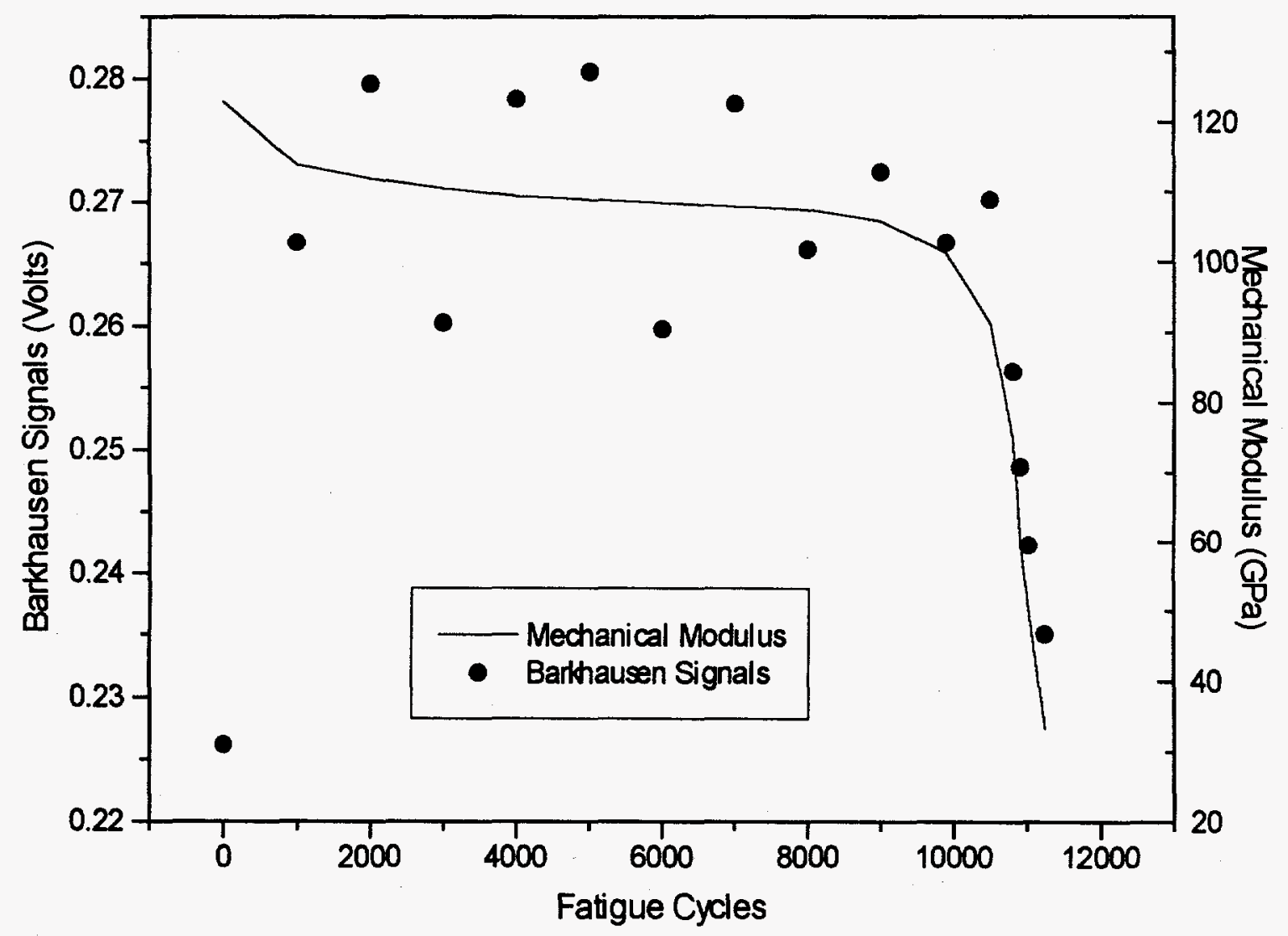

Fig. 16 The effect of strain-controlled fatigue on Barkhausen emissions in one specimen machined from first A533B steel normal to rolling direction ( group B ). 


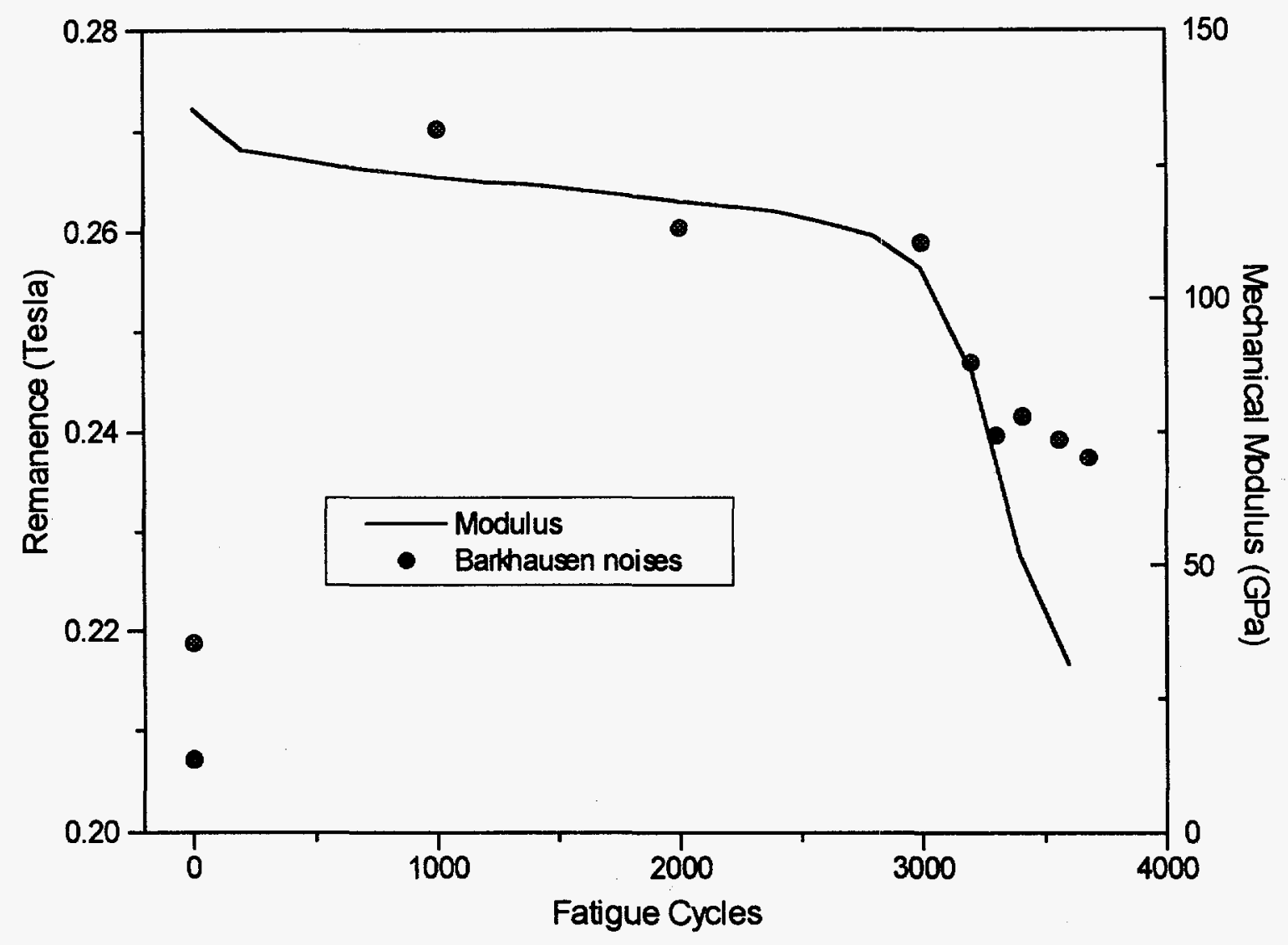

Fig. 17 The effect of strain-controlled fatigue on Barkhausen emissions in one specimen machined from the second A533B steel (Group C) 


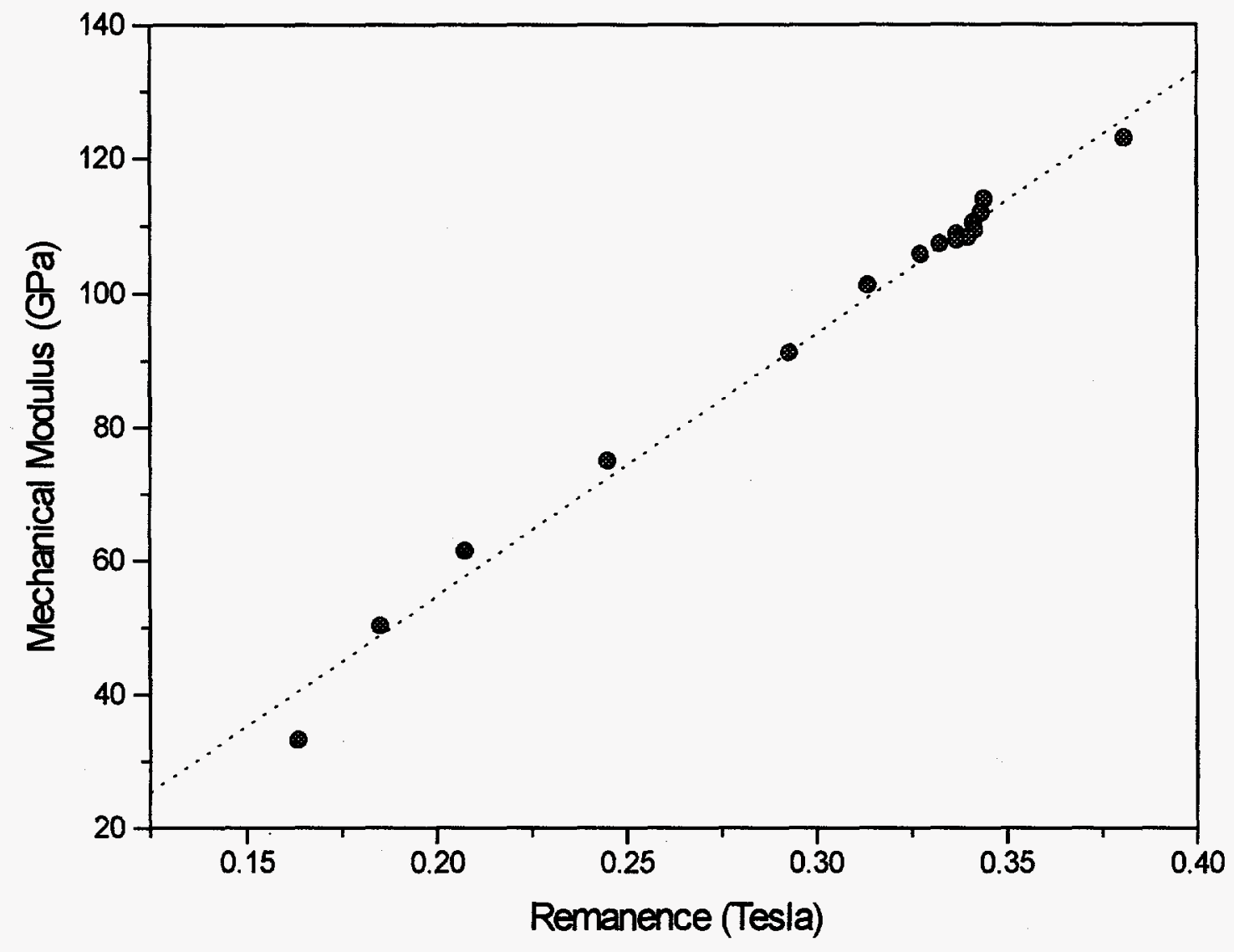

Fig. 18 Relationship between mechanical modulus and measured remanence in straincontrolled fatigue on sample NRC-B5. 


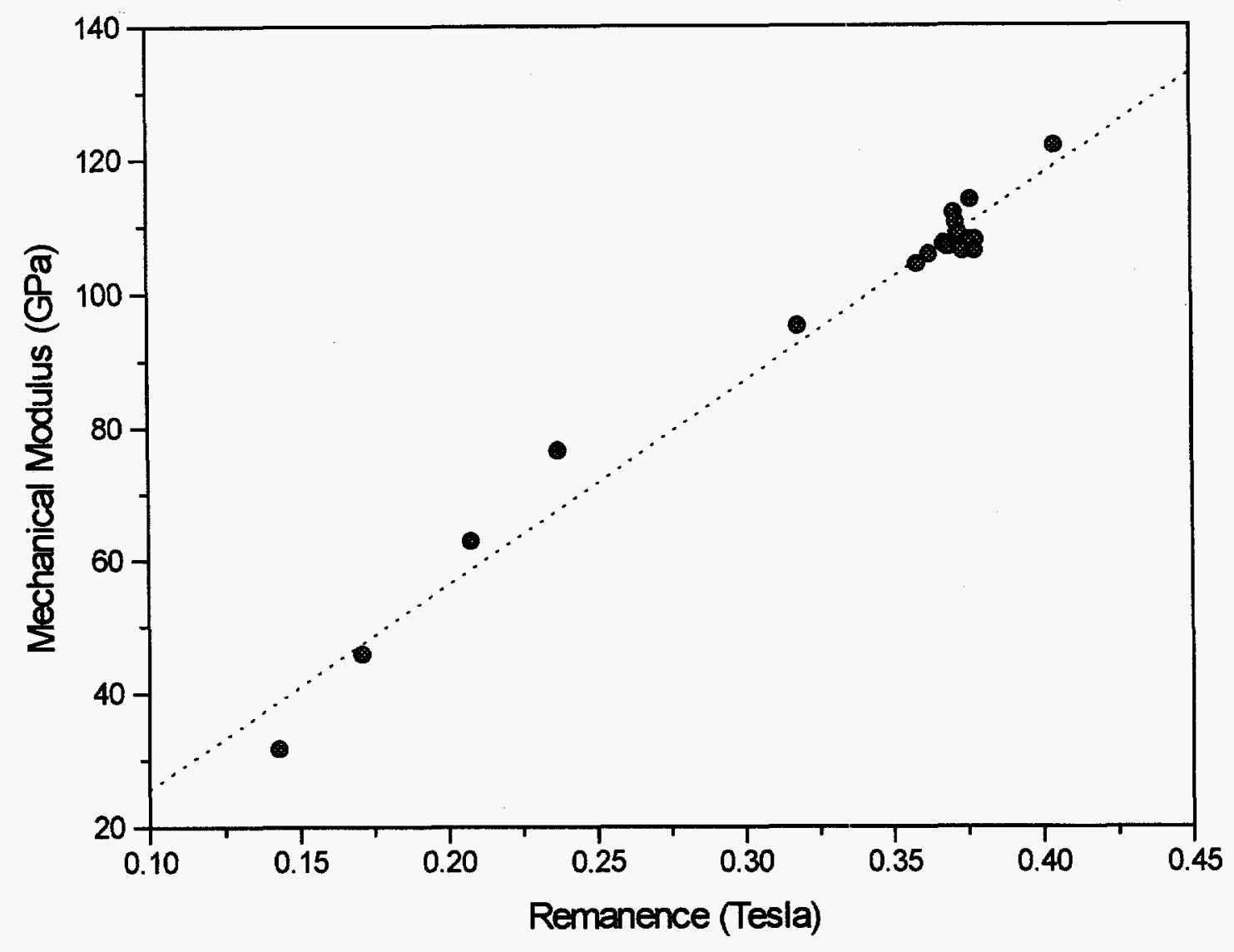

Fig. 19 Relationship between mechanical modulus and measured remanence in straincontrolled fatigue on sample NRC-A5. 


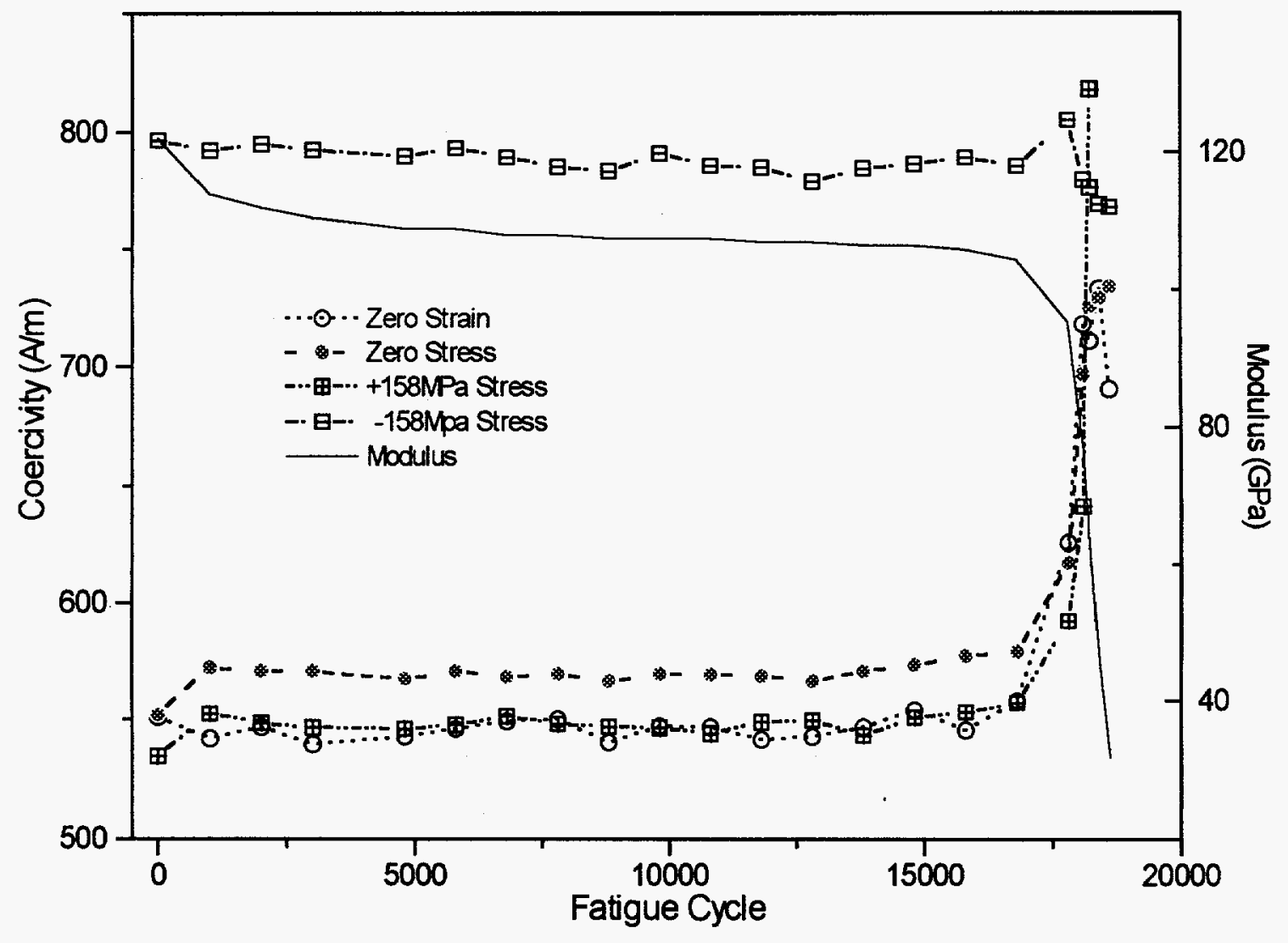

Fig. 20 The effect of both fatigue damage and stress on measured coercivity in straincontrolled fatigue 


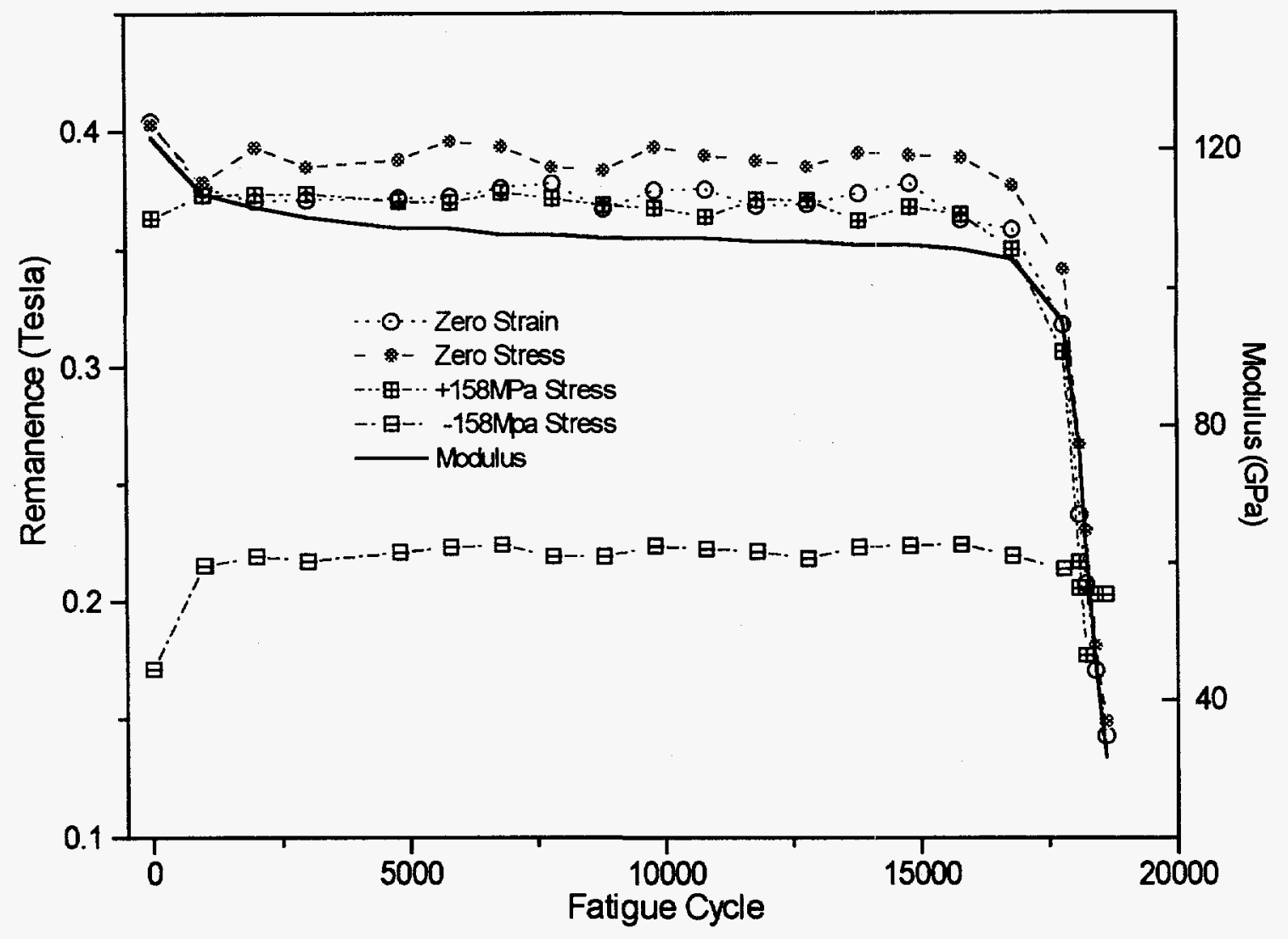

Fig. 21 The effect of both fatigue damage and stress on measured remanence in straincontrolled fatigue 


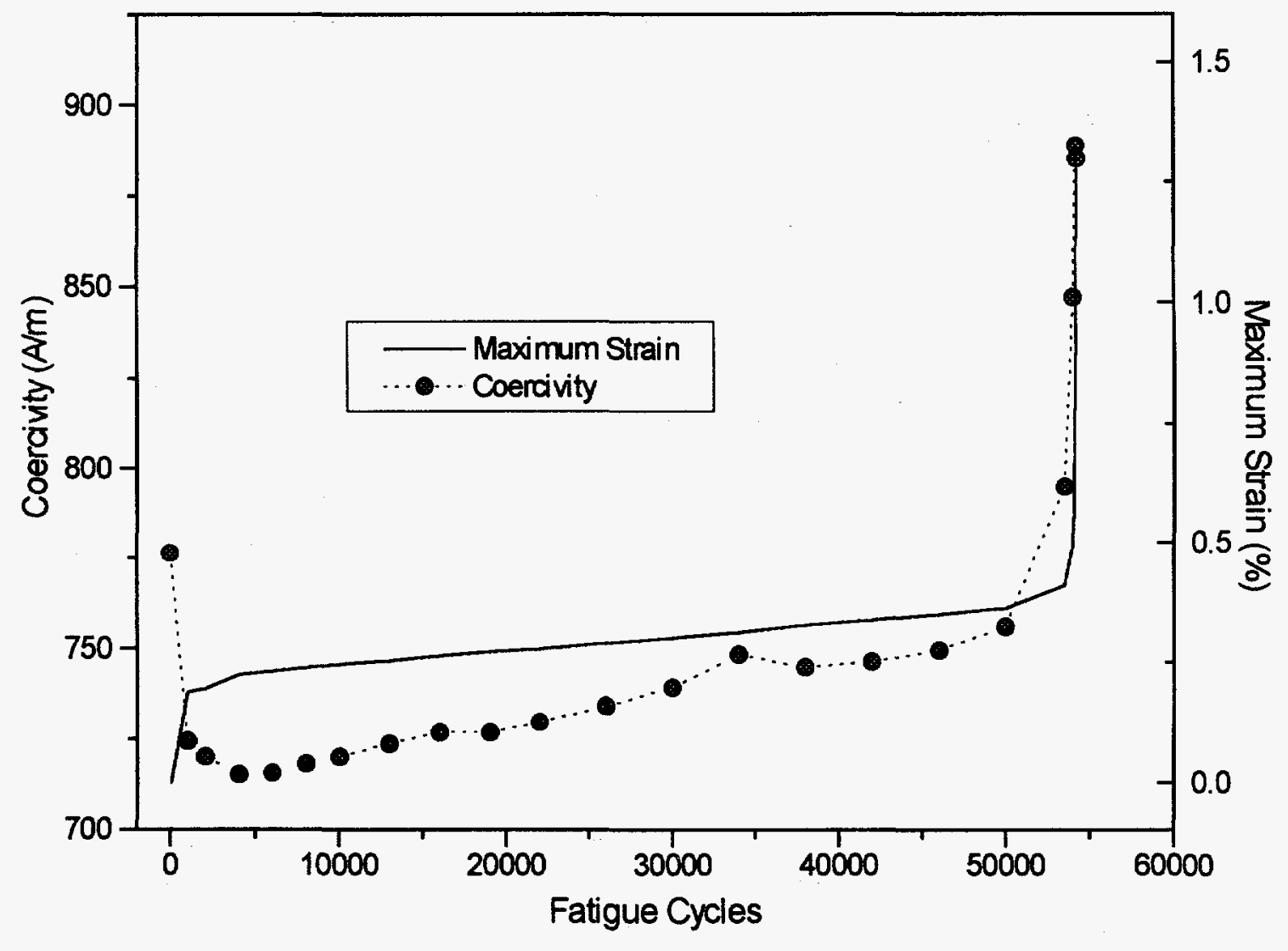

Fig. 22 The effect of fatigue damage on coercivity of A533B steel in load-controlled fatigue 


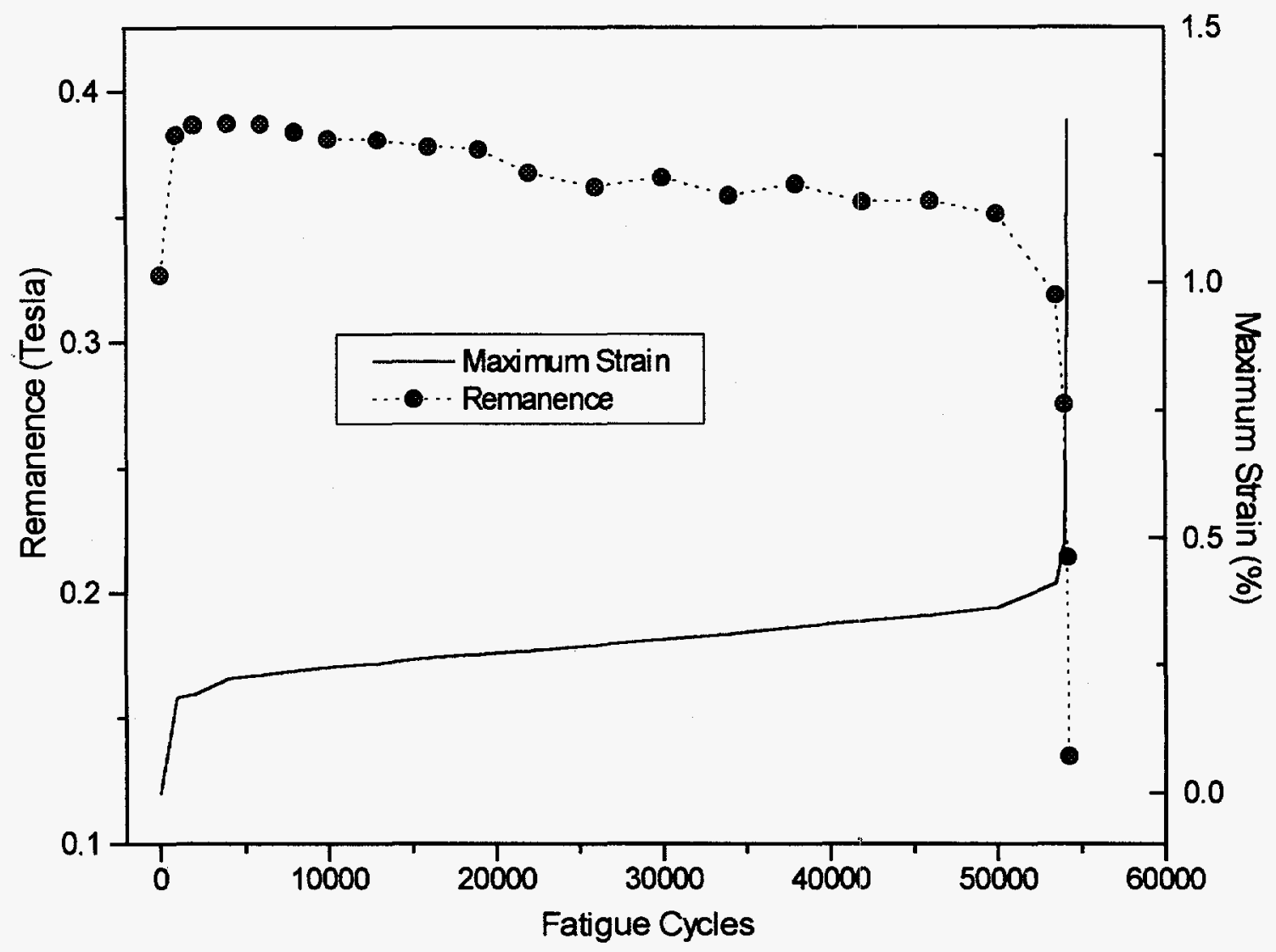

Fig. 23 The effect of fatigue damage on remanence of A533B steel in load-controlled fatigue. 


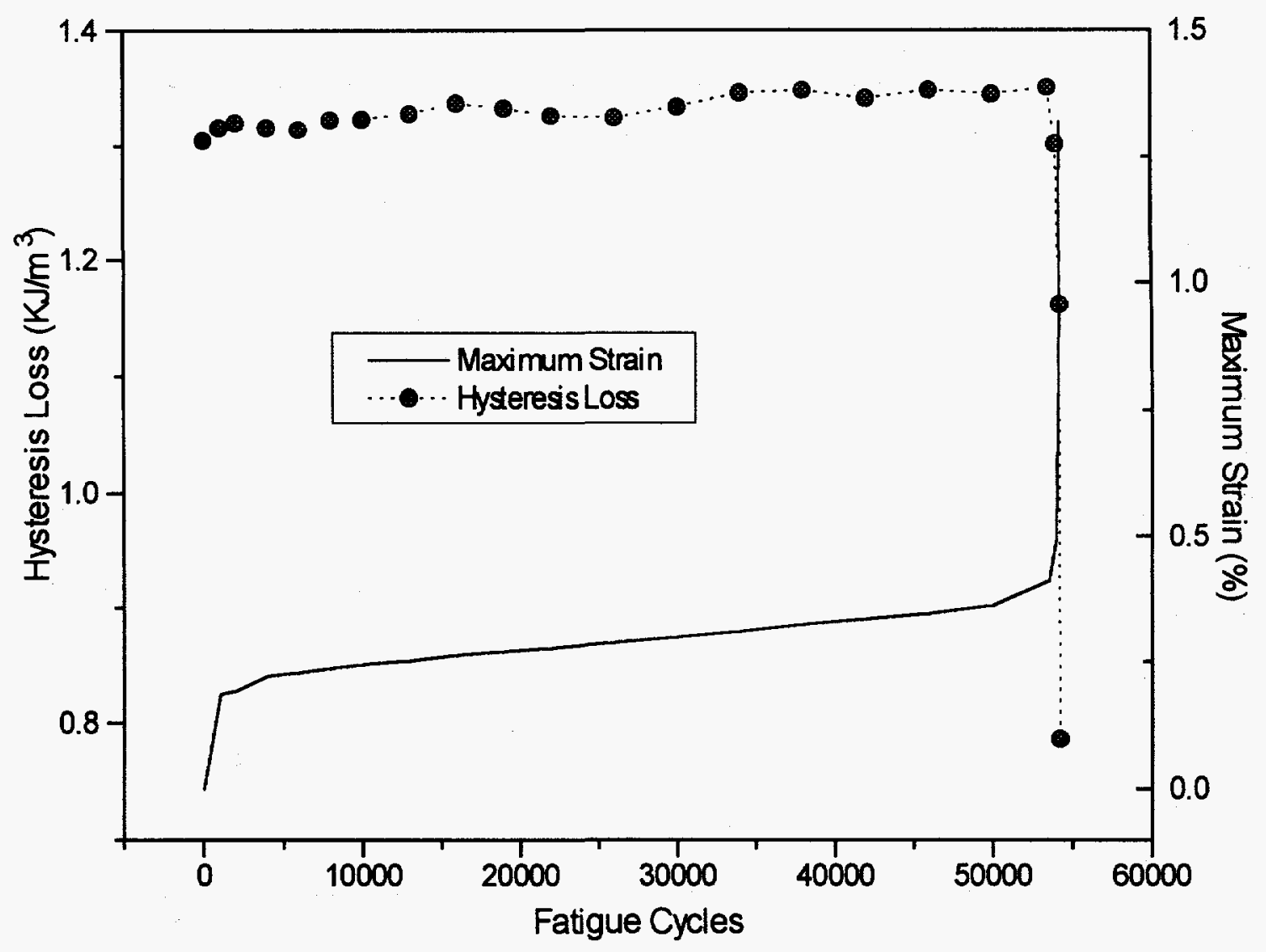

Fig. 24 The effect of fatigue damage on hysteresis loss of A533B steel in load-controlled fatigue. 


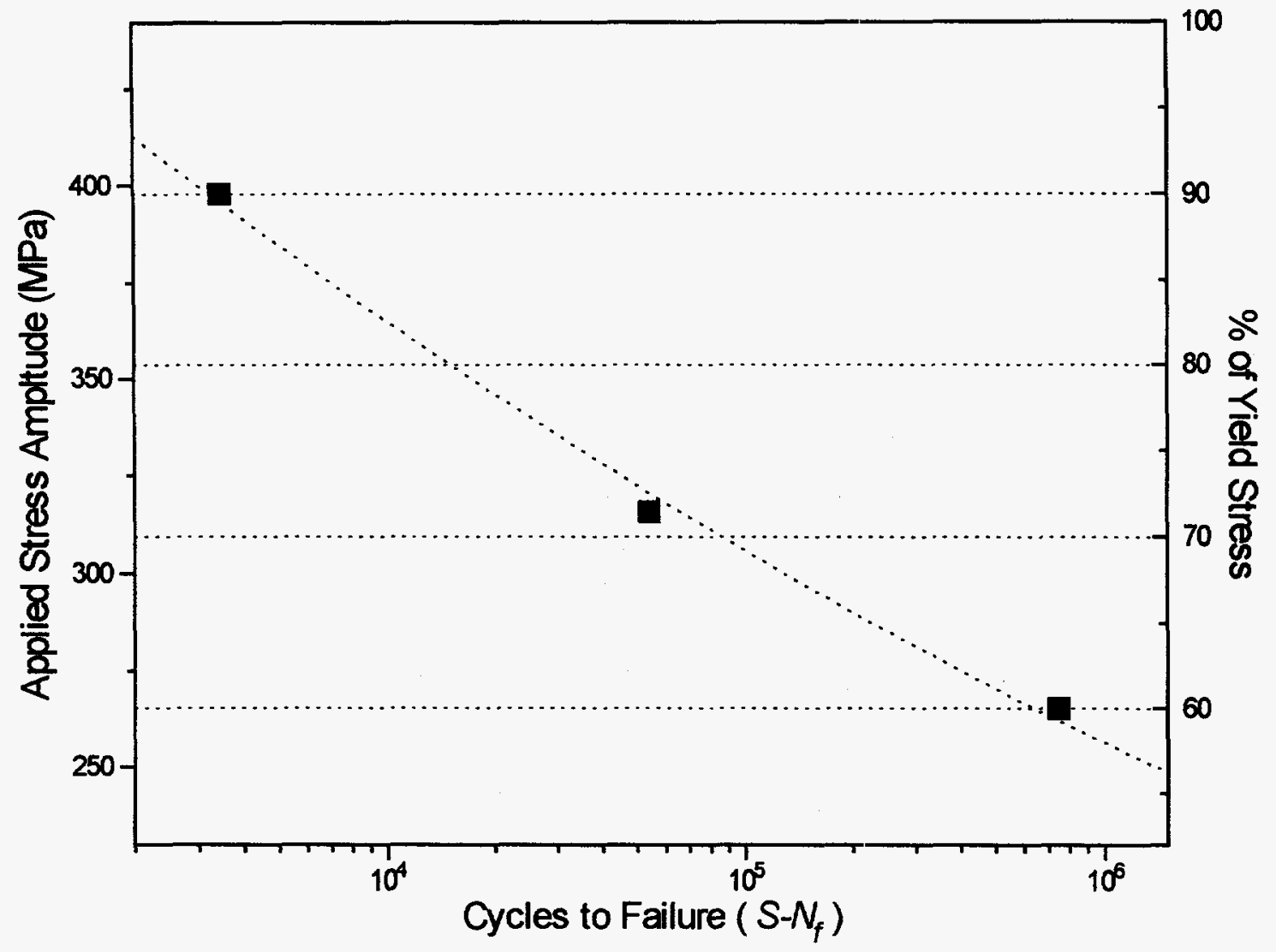

Fig. 25 The Wöhler curve ( $S-N_{f}$ curve) of A533B steel in load-controlled fatigue. 


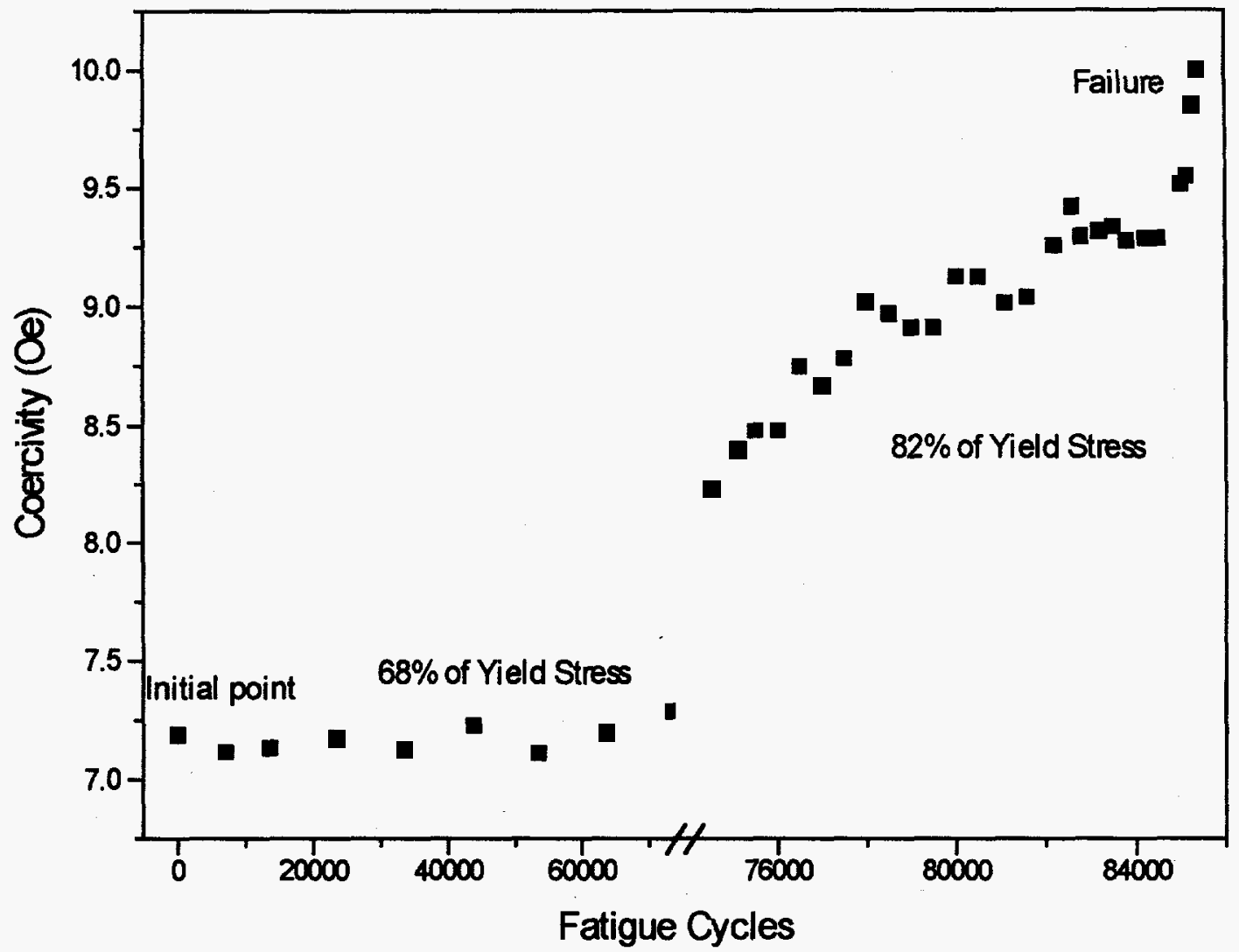

Fig. 26 The effect of cyclic loading amplitude on the evolution of the magnetic properties ( coercivity) in the A533B steel. 


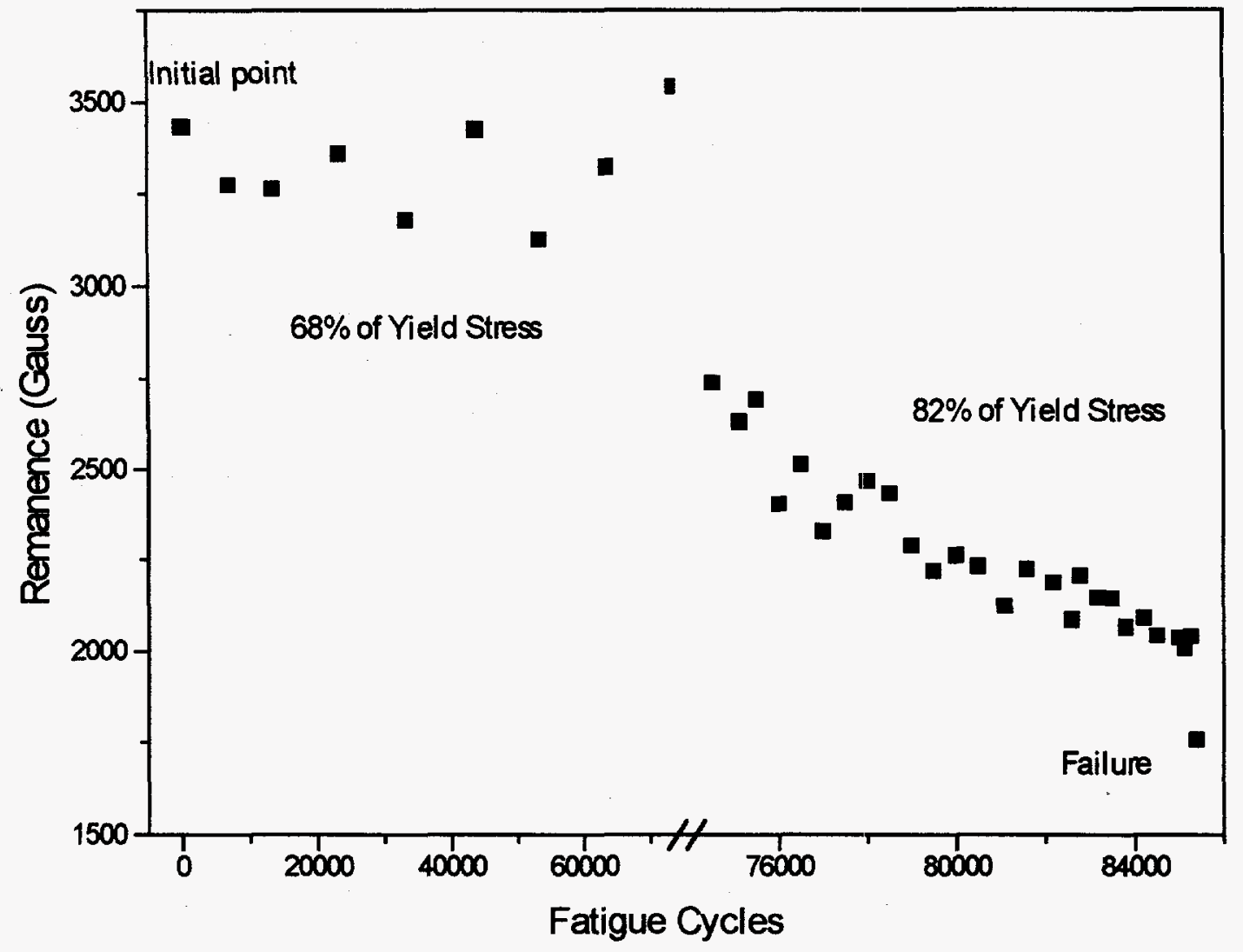

Fig. 27 The effect of cyclic loading amplitude on the evolution of the magnetic properties ( remanence) in the A533B steel. 


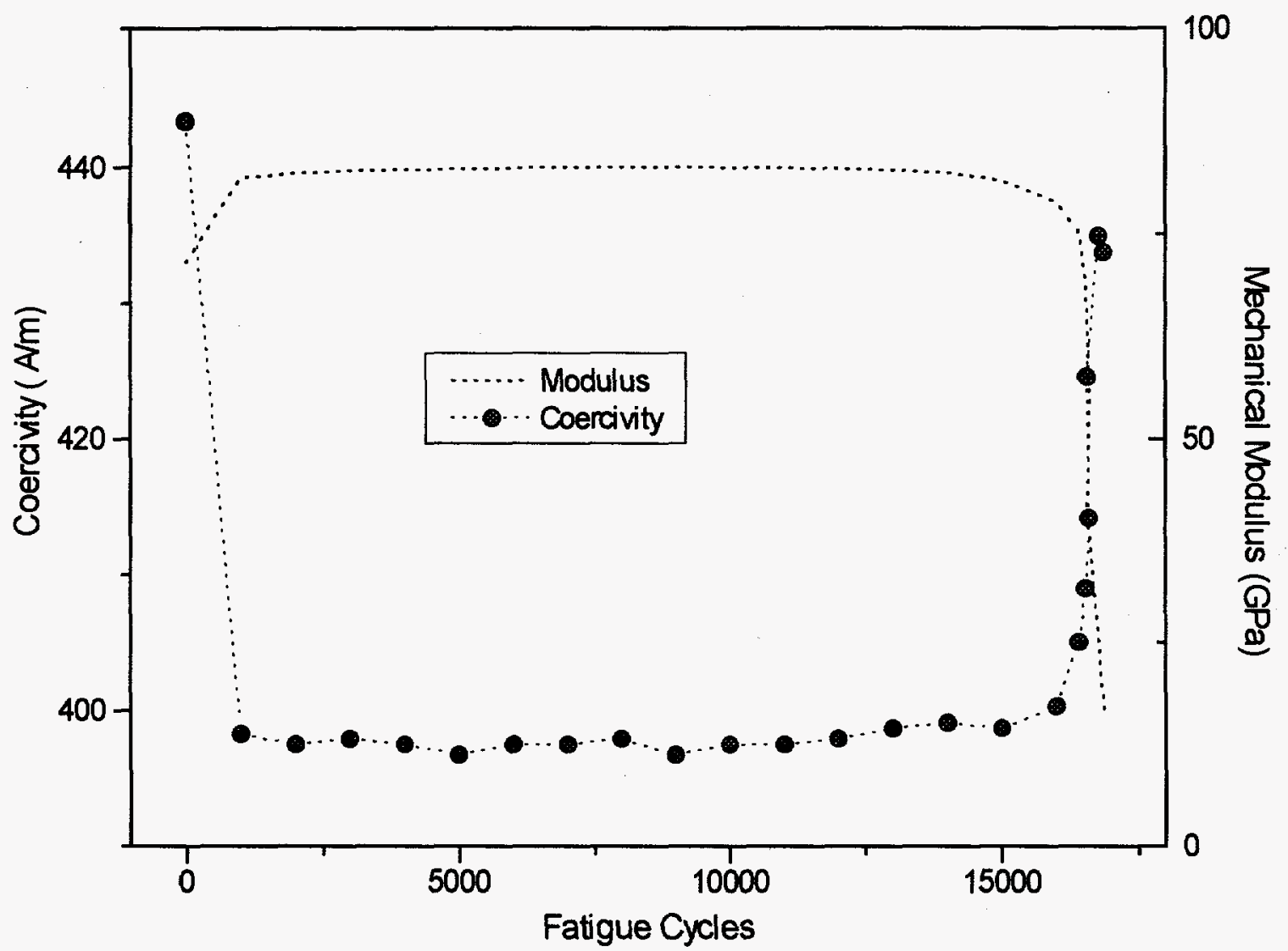

Fig. 28 The effect of strain-controlled fatigue on magnetic coercivity in one specimen (NRC-E1) machined from Cr-Mo steel.

Test \#: FTG-M; sample: NRC-E1 


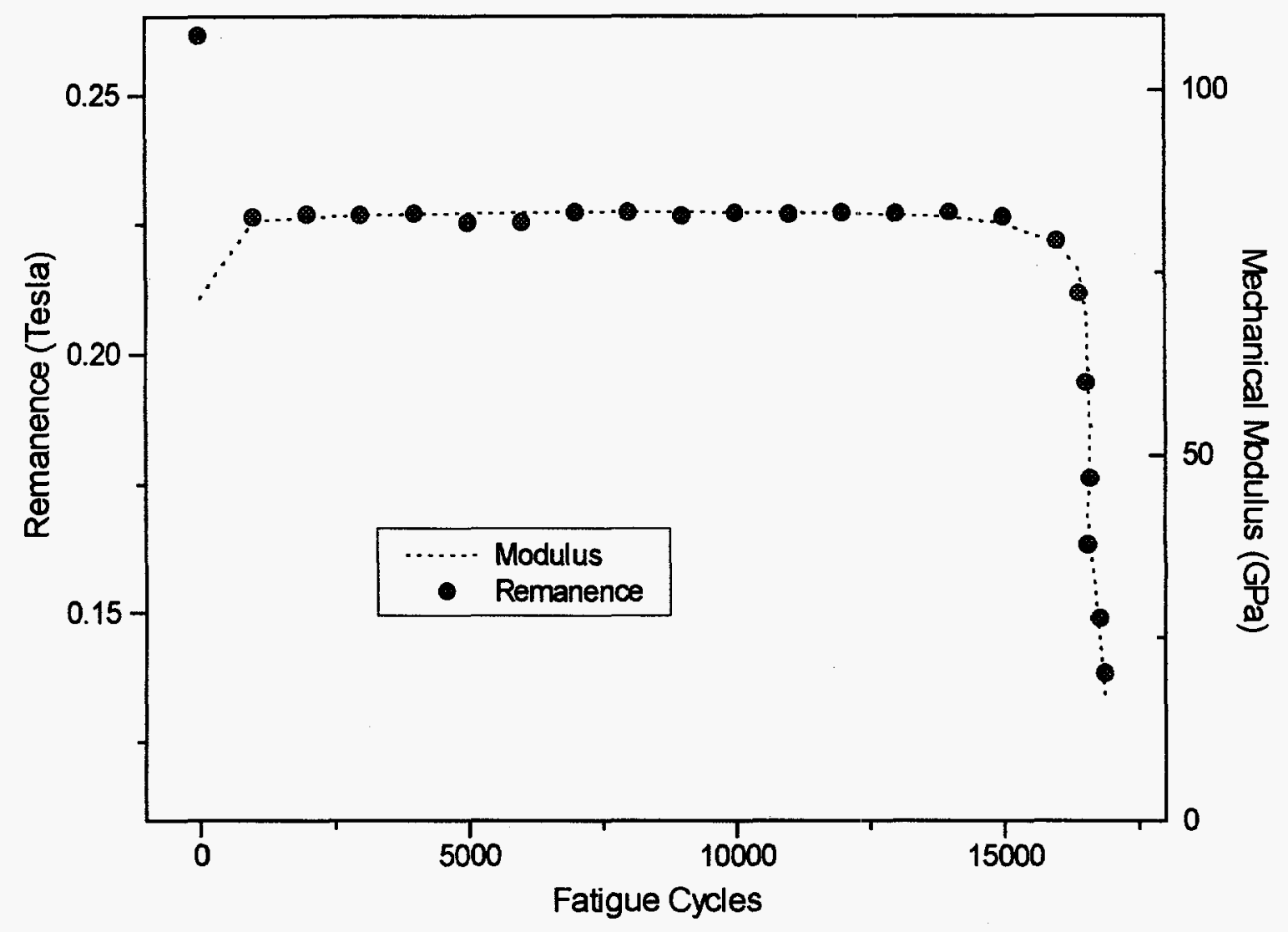

Fig. 29 The effect of strain-controlled fatigue on magnetic remanence in one specimen (NRC-E1) machined from Cr-Mo steel

Test \#: FTG-M; sample: NRC-E1 


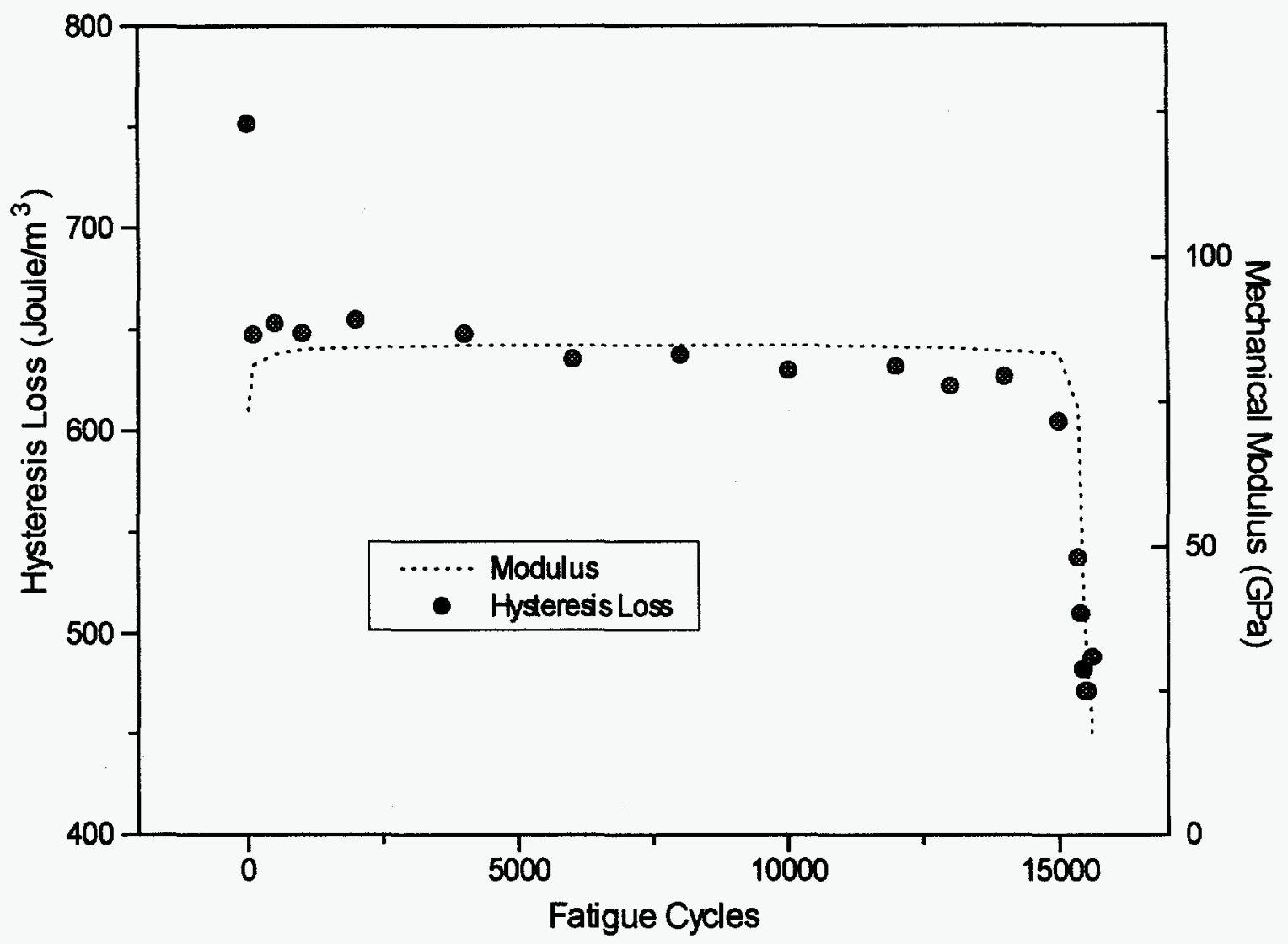

Fig. 30 The effect of strain-controlled fatigue on hysteresis loss in one specimen machined from Cr-Mo steel.

Test \#: FTG-N; sample: NRC-E3 


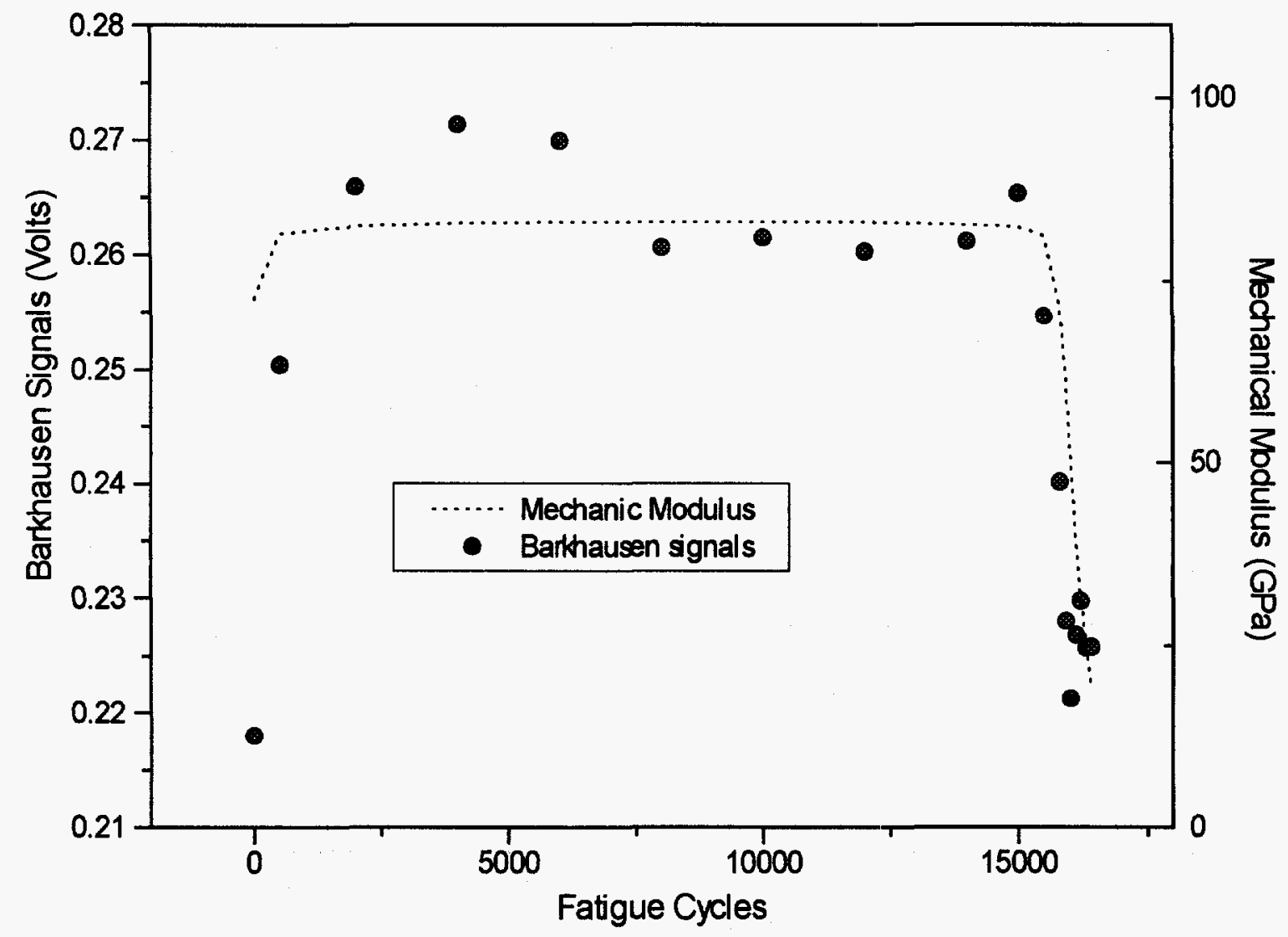

Fig. 31 The effect of strain-controlled fatigue on Barkhausen emissions in one specimen machined from Cr-Mo steel.

Test \#: FTG-O; sample: NRC-E6 


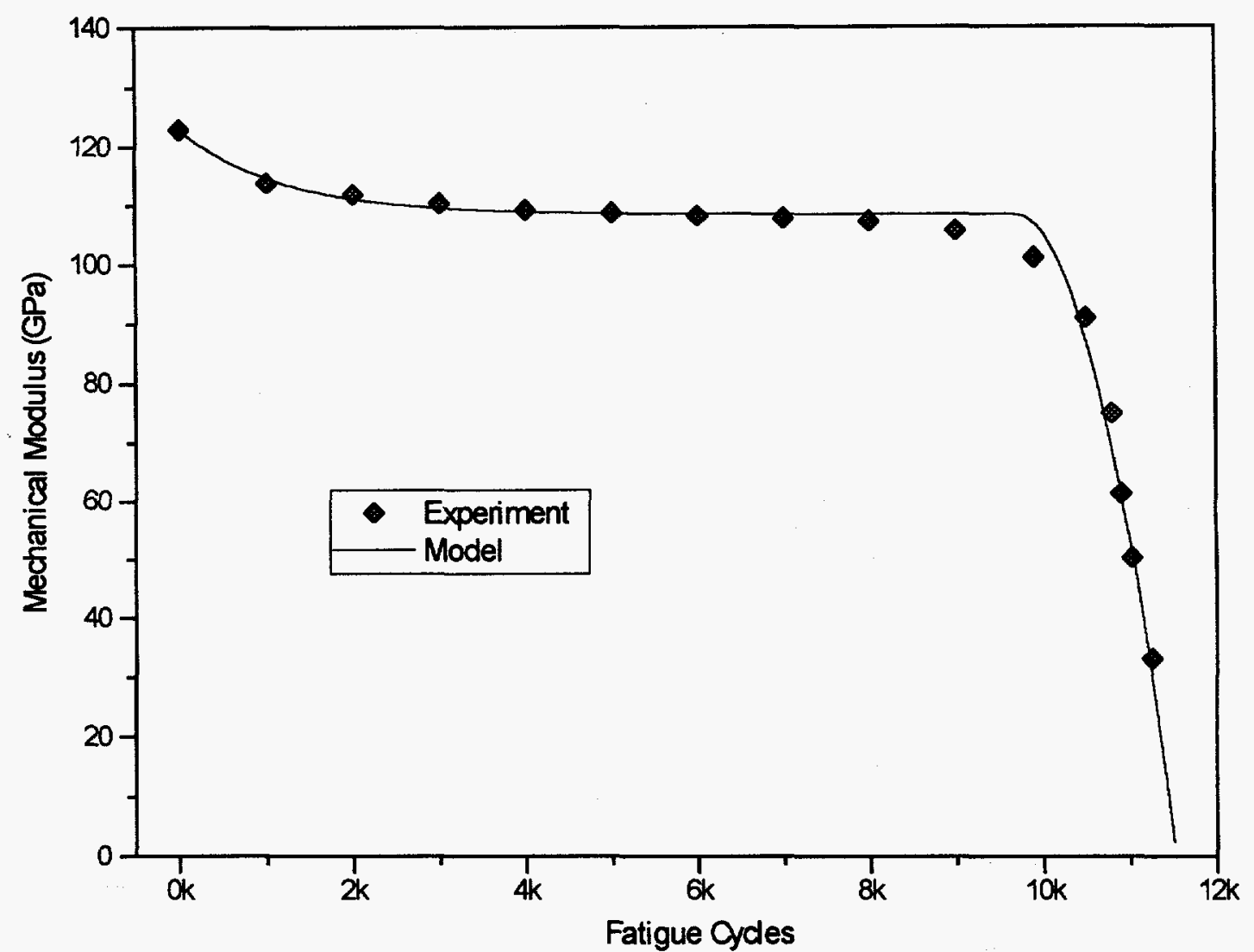

Fig. 32 Experimental and modeled curves about the dynamic change in mechanical modulus resulted from strain-controlled fatigue damage

Test \# FTG-9; Sample: NRC-B5 


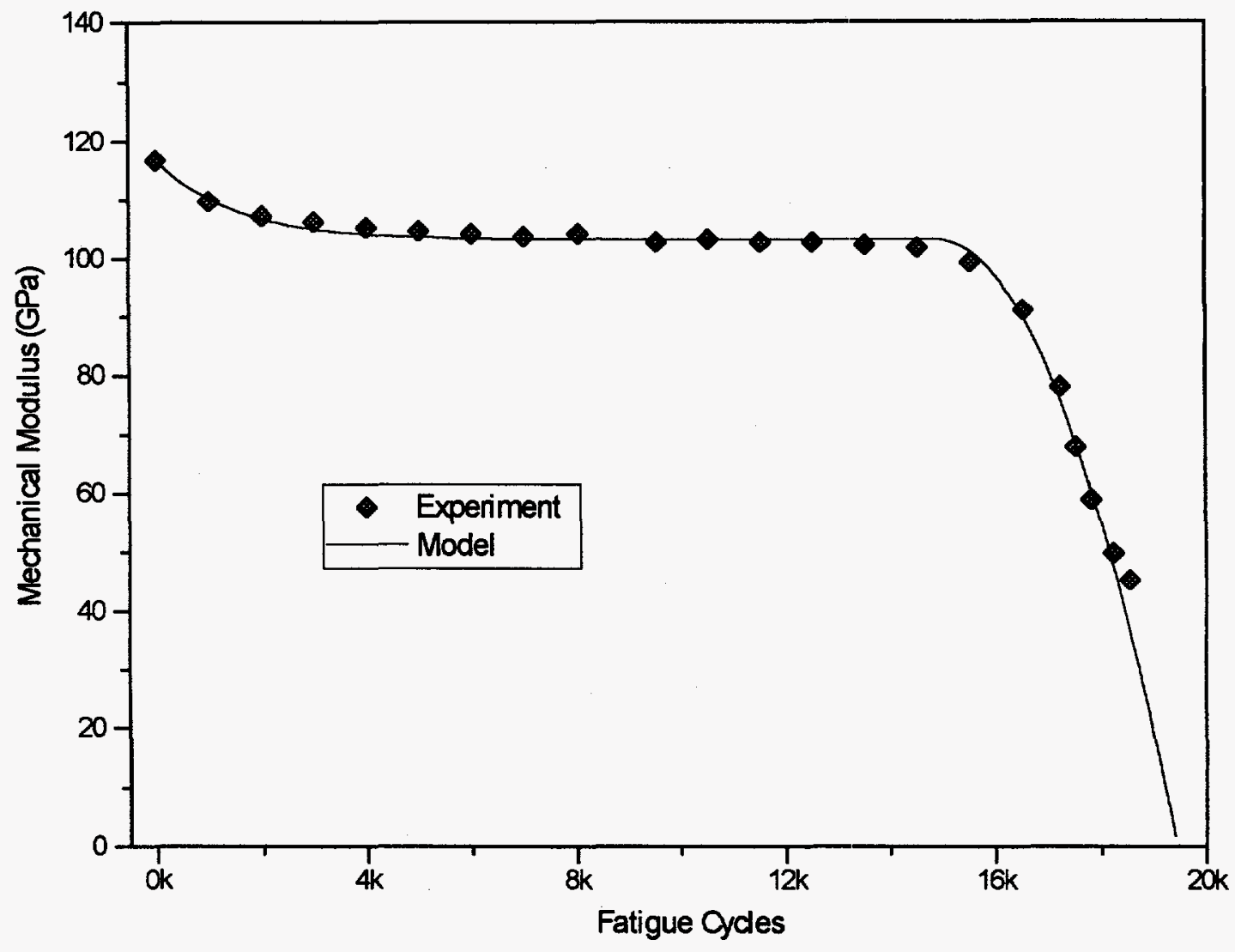

Fig. 33 Experimental and modeled curves about the dynamic change in mechanical modulus resulted from strain-controlled fatigue damage

Test \# FTG-8; Sample: NRC-A5 


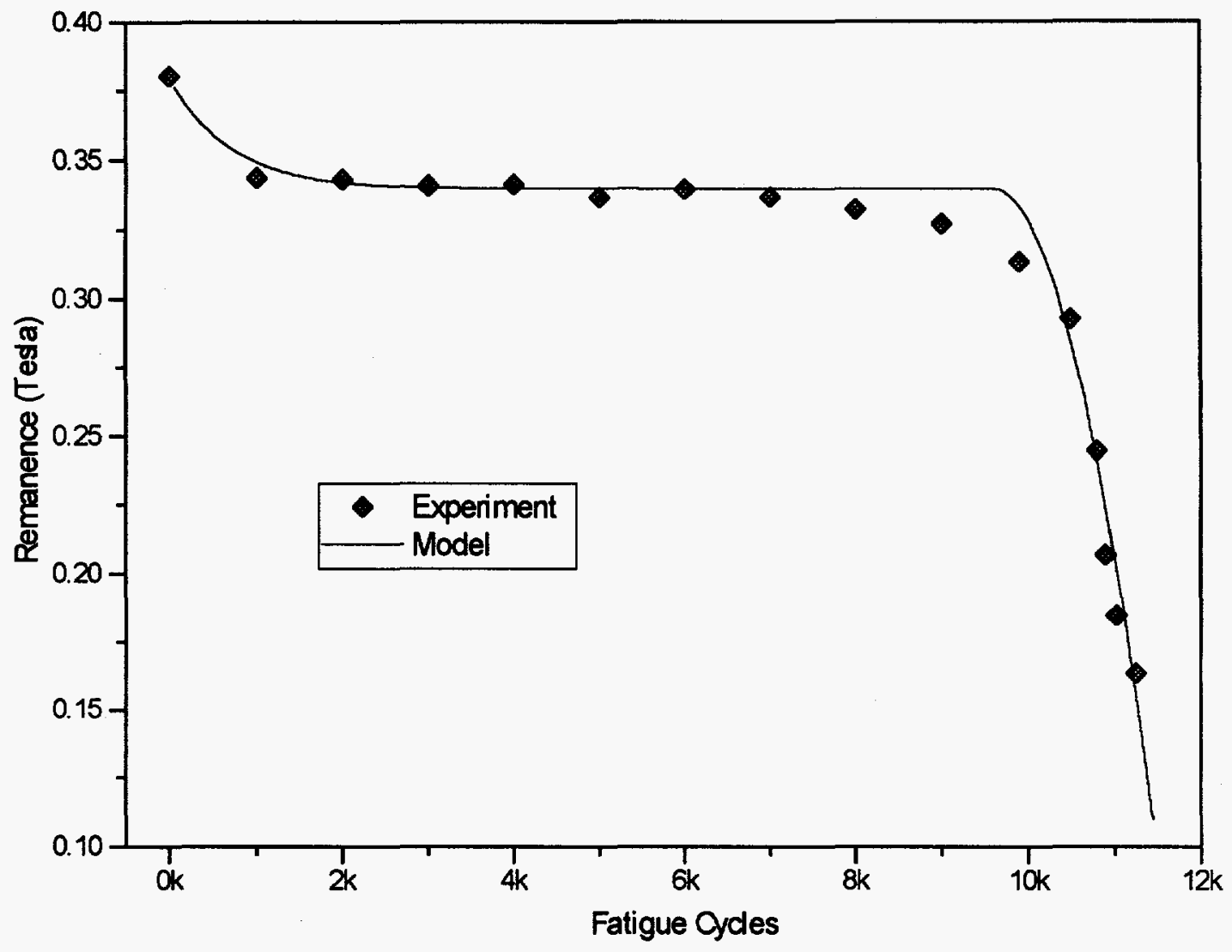

Fig. 34 Experimental and modeled curves about the dynamic change in measured remanence resulted from strain-controlled fatigue damage

Test \# FTG-9; Sample: NRC-B5 


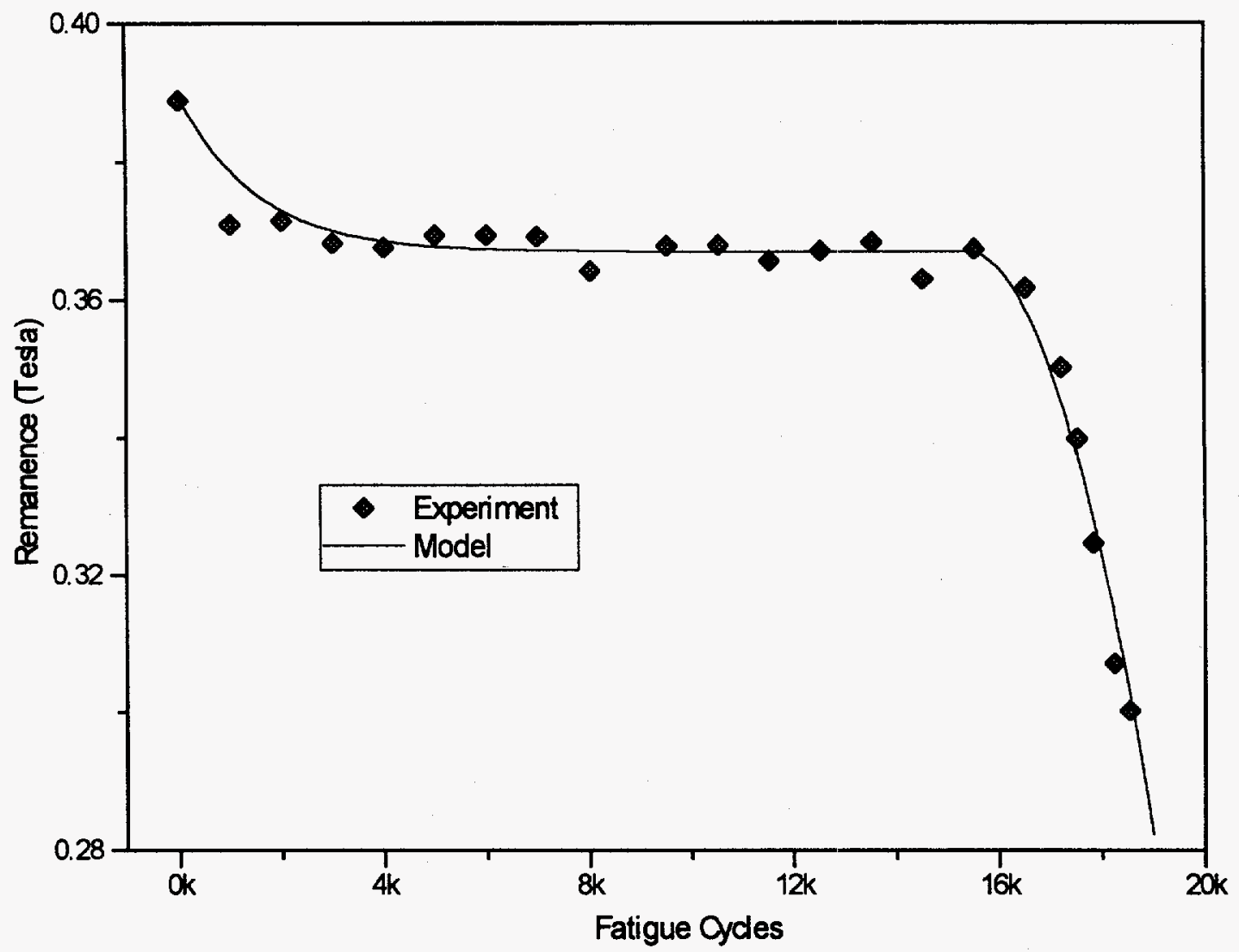

Fig. 35 Experimental and modeled curves about the dynamic change in measured remanence resulted from strain-controlled fatigue damage

Test \# FTG-8; Sample: NRC-A5 


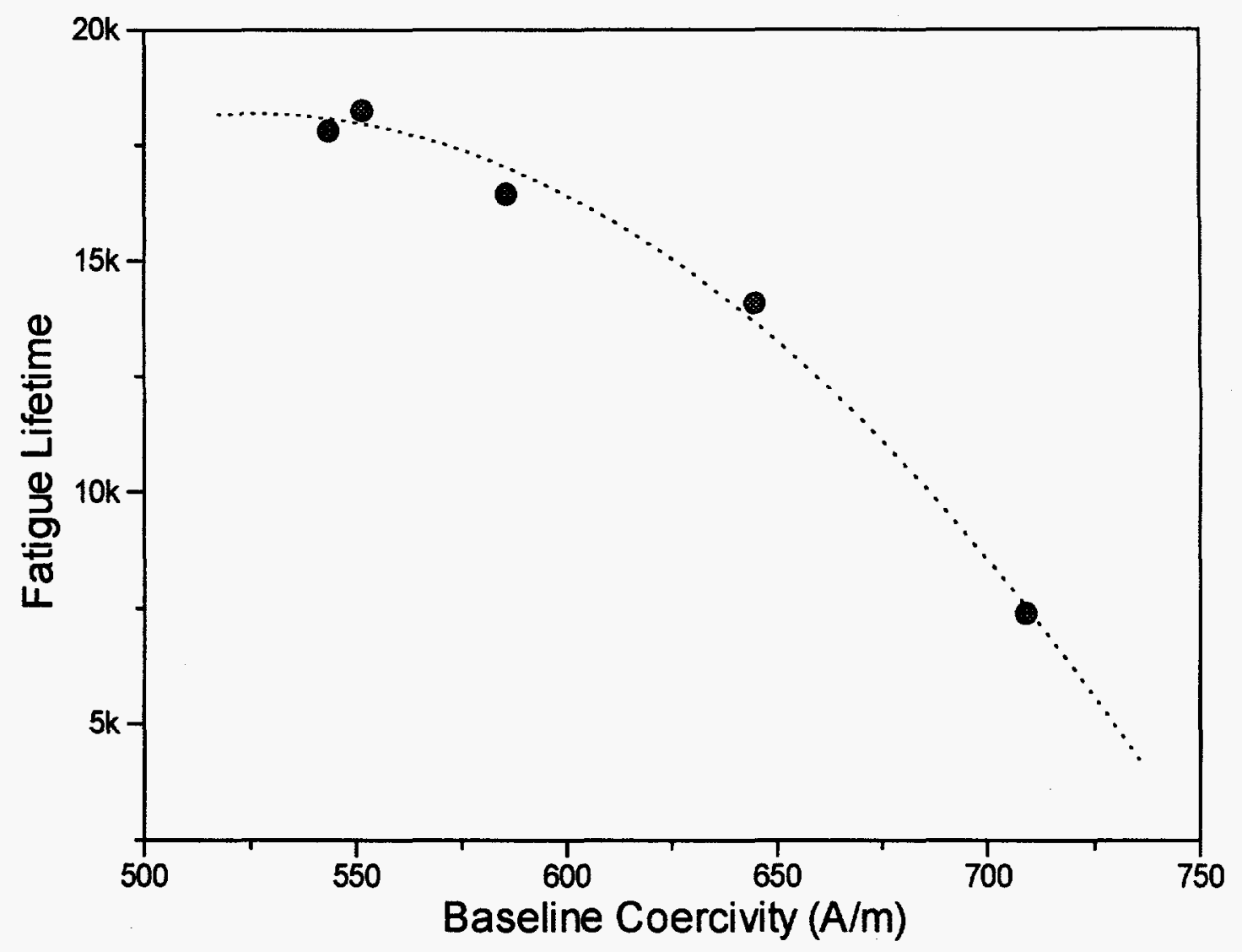

Fig. 36 Relation between the fatigue lifetime and baseline coercivity in one group of A533B steel. 



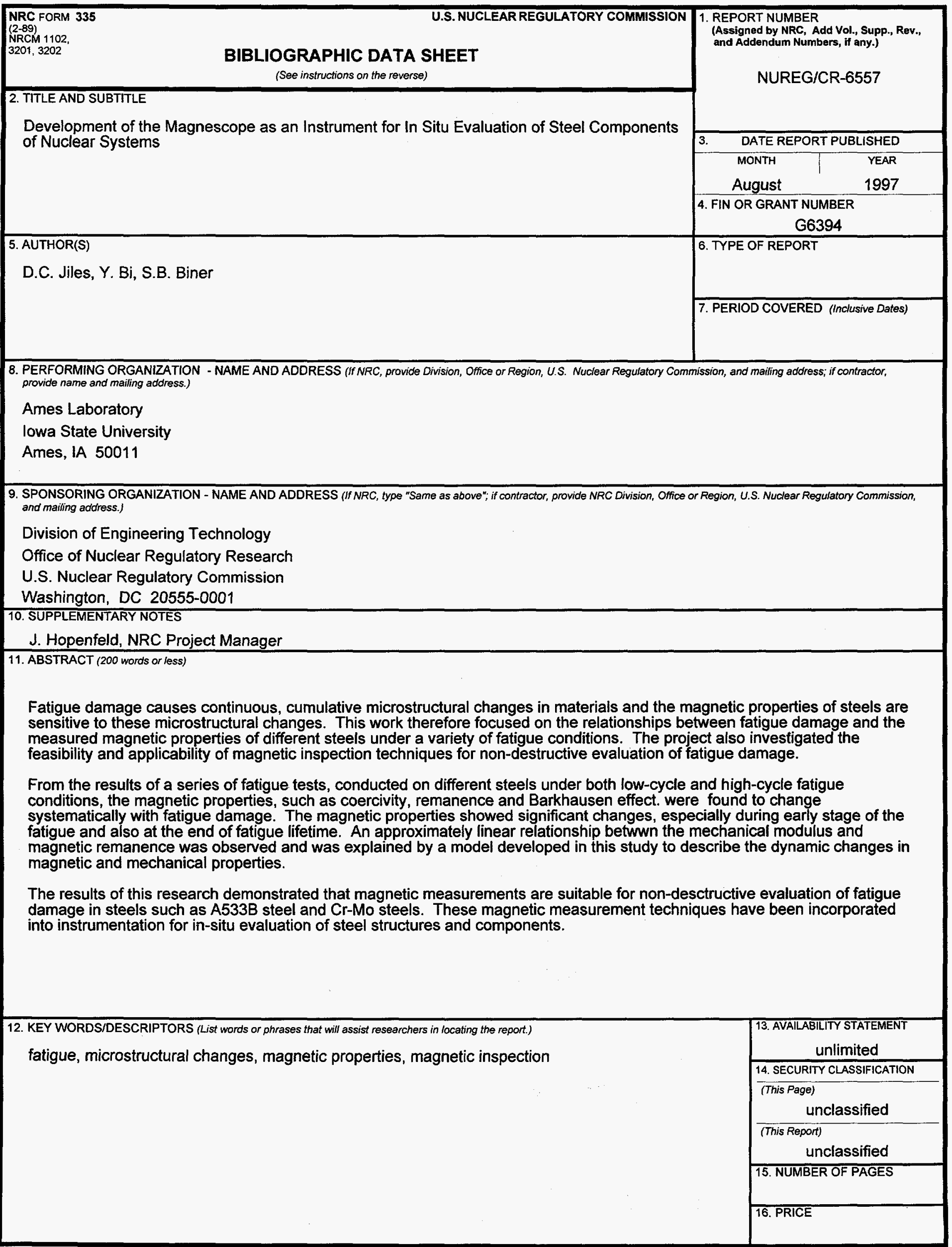




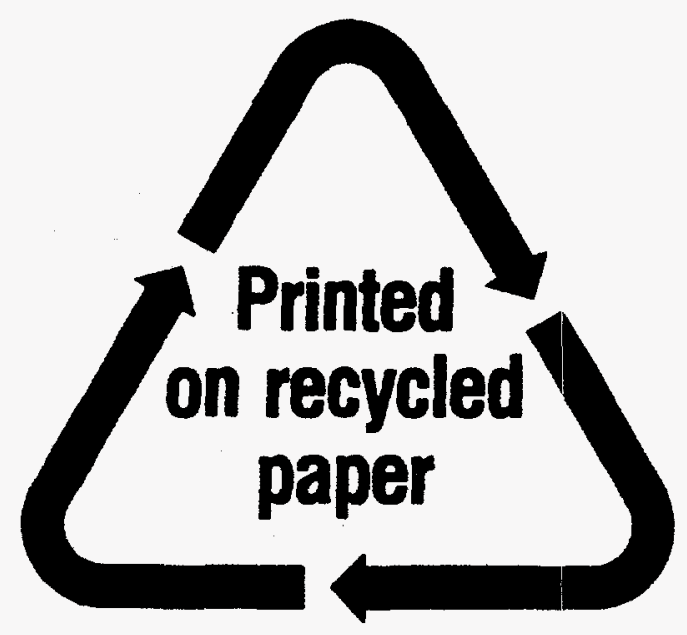

Federal Recycling Program 